Review Article

Open Access

\title{
The Synthesis of Ribose and Nucleoside Derivatives
}

\author{
Nermin Şimşek Kuş \\ Mersin University Department of Chemistry Mersin 33343 Mersin, Turkey
}

\section{Article Info

\author{
*Corresponding author: \\ Nermin Şimşek Ku \\ Professor \\ Department of Chemistry \\ Mersin University \\ Mersin 33343 \\ Turkey \\ Email: simner@gmail.com
}

Received: November 3, 2017

Accepted: March 12, 2018

Published: March 16, 2018

Citation: Kuş NS. The Synthesis of Ribose and Nucleoside Derivatives. Madridge J Nov Drug Res. 2018; 2(1): 37-56.

doi: $10.18689 / \mathrm{mjndr}-1000107$

Copyright: $(2018$ The Author(s). This work is licensed under a Creative Commons Attribution 4.0 International License, which permits unrestricted use, distribution, and reproduction in any medium, provided the original work is properly cited.

Published by Madridge Publishers

\begin{abstract}
Ribose and nucleoside derivatives are important molecules used as drugs. They are structural subunits of nucleic acids and usually obtained by chemical or enzymatic decomposition of nucleic acid. These derivatives are important organic molecules used in the transport of genetic information in living cells. For example, antiviral drugslike a cyclovir are used to prevent viral replication in infected cells. The importance of synthesis of nucleoside, considering probiotics, is increasing because of medical usage for 50 years for patients with cancer or viral infections. The $\beta$-D-ribofuranose form of ribose is normal sugar and forms the backbone of RNA. Phosphorylated ribose derivatives such as ATP play important roles in metabolism. Although this study is concerned with the synthesis of ribose and nucleoside derivatives in literature, novel derivatives and methods for the synthesis of ribose and nucleoside analogues are still needed due to their biological importance in synthetic organic chemistry. This review covers the synthesized ribose and nucleoside analogues in literature reported from 1914 up to this day.
\end{abstract}

Keywords: Ribose; Nucleoside biological activity; Drug; Medicine

\section{Introduction}

Ribose synthesized fromthe living body an organic compound classified as a monosaccharide is used as medicine and is also found in RNA as a kind of sugar (Scheme 1), for example, ribonucleotides, nucleic acids, riboflavin, etc. Nucleotides are important macromolecules that convey genetic information in cells. At the mean time, they are the molecular building blocks of DNA and RNA. Many nucleosides represent important classes of antineoplastic and antiviral therapeutics.

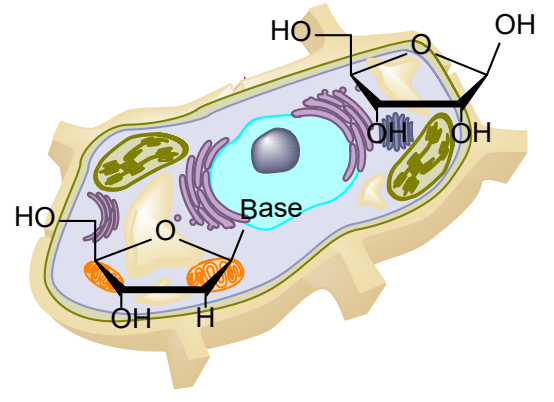

Scheme 1. Ribose (1) and Nucleoside (2)

Prostacyclins (3) are molecules with potent aggregation-inhibitory, anti-inflammatory, and antiproliferative properties [1]. The poly (adenosine diphosphate [ADP]-ribose) polymerase plays a key role in the repair of DNA single-strand breaks and the repair of base excisions [2]. There are antitumor and antiviral effect of some natural carbocyclic nucleosides [1e] like aristeromycin [3] (4), neplanocin A [4] (5), carbovir [5] (6), abacavir 
[6] (7), cyclopentenyl cytosine [7] (8), 2'deoxy-ribofuranosyl nucleosides [8] (9) and arabinofuranosyl nucleosides [8] (10).
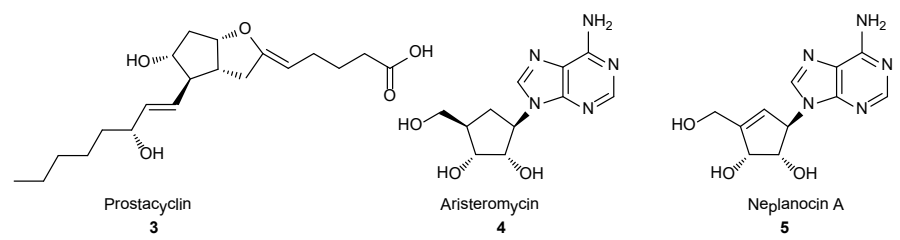
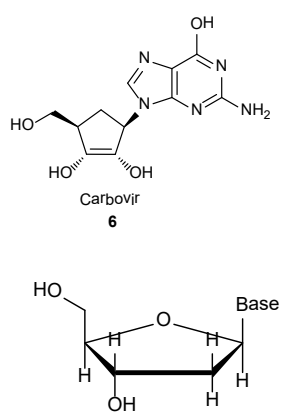

2-deoxy ribofuranosyl nucleoside 9

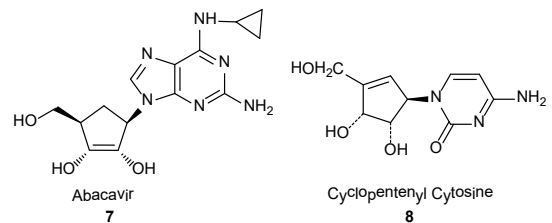

8

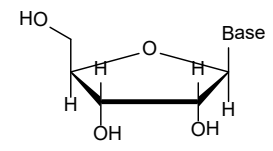

Arabinoribofuranosyl nucleoside 10

Scheme 2. Some of the effects of antitumor and antiviral molecules $[1,2,3,4,5,6,7,8,9,10]$.

It is also known that $3^{\prime}$-azido-3'deoxythymidine [9] (11) and 2', 3'-dideoxynucleosides [10] (12) are effective against the acquired immune defiency syndrome (AIDS) and a therapeutic agent (Scheme 2).

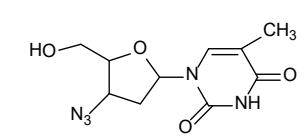

3'-azido-3'-deoxythymidine 11

Scheme 3. Biological active molecules 11 and $12[9,10]$.

\section{Synthesis of Ribose and NucleosideDerivatives year by year}

In 1914, Fischer and Helferich did studies on the synthesis of D-glukopyranosidoadenin with a method called "modification of Fischer and Helferich" [11]. In 1929 and 1930, Hilbert and Johnson disclosed a method for the synthesis of nucleosides which can be applied to other ring systems such as quinolones, pyridines and pyrazolones [12]. In 1937, Levene and Compton wrote an article on the synthesis of theophyllineD-allomethyloside [13].

In 1946 and 1947, Howard et al. developed a method for the synthesis of adenosine and purin nucleoside anologs in a series of studies [14]. The synthesis of methyl-D-ribofuranoside was obtained by oxidation in the presence of sodium metaperiodate and methylation by Barker in 1948 [15]. In another study, 2,3,5- trimethyl D-ribose anilide, 3, 5-dimethyl D-ribose phenylzoazome, 2, 3, 5 trimethyl Dribomolactone, and 2, 3, 5 trimethyl D-ribonophenylhydrazide were synthesized with high yields by Baker in 1948 [15].

Friedkin and Kalckar described the isolation and properties of the highly acidic phosphate ester obtained by the phosphorolytic cleavage of purine deoxyribose nucleosides
[16]. The phosphoric acid esters of 2-deoxy-D-ribose are important in biochemical transformain. Racker purified the deoxyribose-5-phosphate aldolase enzyme from E. coli extract and described a way for the biosynthesis of deoxyribose-5-phosphate in 1952 [17]. 2-Deoxy-D-ribose-5phosphate aldolase (DERA) is widely found in animal tissues and microorganism. DERA is obtained from the aldol condensation of glyceraldehyde-3-phosphate and acetaldehyde. Kalckar explained that phosphoglycosyl compounds (ribose-1-phosphate, deoxyribose-1-phosphate and their corresponding 5 -esters) can play a significant role in biosynthesis of nucleosides and nucleotides in the animal organism in 1953 [18]. Baker et al synthesized aminoglycoside purine derivatives starting from D-xylose, including the synthesis of puromycine (13), an aminonucleoside (1953; 1954) (Scheme 4) [19].

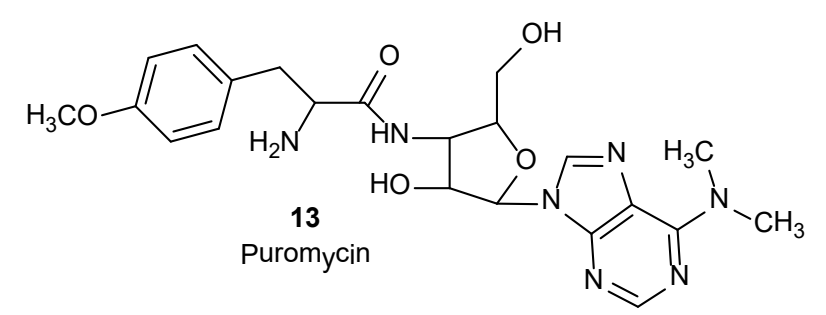

Scheme 4. Puromycin an aminodeoxyglycosido purine derivative [19].

In the following years, in 1954, Ness et al. succeeded in preparing 2, 3, 5-tri-o-benzoyl-b-b-ribose from $\mathrm{D}$-ribose as a stable precursor for the synthesis of D-ribofuranoside and benzyl-b-D-ribofuranoside tribenzoate derivativesat high yield [20]. Friedkin and Roberts succeeded in the enzymatic synthesis of thymidine, $\mathrm{C}^{14}$-thymidine and related pyrimidine nucleoside derivatives, reacting thymine with deoxyribose-1-phosphate, in 1954 [21a]. Friedkin described the isolation and synthesis of azaguanine riboside and azaguanine deoxyriboside, nucleoside obtained by the enzymatic reaction between 8 -azaguanine and ribose-1-phosphate or deoxyribose-1-phosphate in the same year [21b]. Mowery reported the successful use of acidic ion exchange resins as catalysts in glycoside formation with the Fischer method in 1955 [22]. Cardwell and Kilner [23] than Barker et al [24] succeeded in synthesizing methyl ethers of ribose and its derivatives. Kissman et al. synthesized D-ribofuranosyl derivatives of 6-dimethylaminopurine in 1955 [25]. Baker studied puromycin andribose chemistry with different groups [26].

In 1957, Kissman and Baker disclosed the synthesis of 1, 2, 3-tri-O-acetyl-5-Deoxy-D-ribofuranosylpurines, which is obtained in three steps by methyl 2, 3-O-isopropylidene-5-Omesyl-D-ribofurnoside [27]. In 1958, Shaw et al. synthesized derivatives of purine, pyrimidine and glyoxalines, which are used in the synthesis of ribofuranosides and b--Dribofanosylamines [28]. A deoxyribose phosphate aldolase is specially important since it is used as an enzyme. Mac Donald and Fletcher described the conversion of 2-deoxy-D-ribose (14) to 2-deoxy-D-ribose 5-phosphate (15) in 1959 (Scheme 5) [29]. 


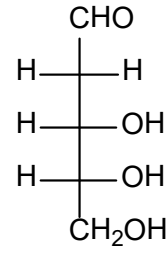

14
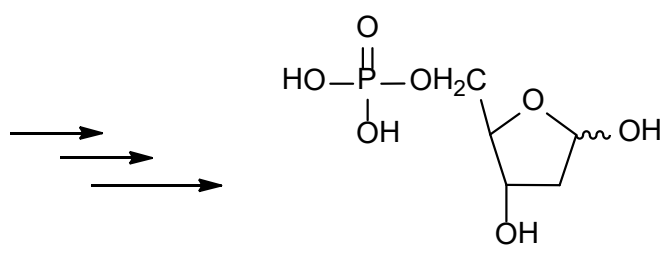

15
Scheme 5. The synthesis of 2-deoxy-D-ribose 5-phosphate (15) [29].

The synthesis of various glycofuranse derivatives was accomplished by acid-catalyzed condensation by reducing sugar with simple alcohol to form alkyl glycofuranosides for a long time. Ness et al. studied the synthesis of 2-deoxy-3, 5-di-O-pnitrobenzoyl-D-ribose (17), 2-deoxy-D-ribofuranose tri- $p$ nitobenzoate (18), isopropyl 2-deoxy-3, 5-di-O-p-nitrobeenzoylD-ribosides $(19,20)$ using crudemethyl2-deoxy-D-ribofuranoside (readly prepared from free sugar 16) in 1961 (Scheme 6) [30a].

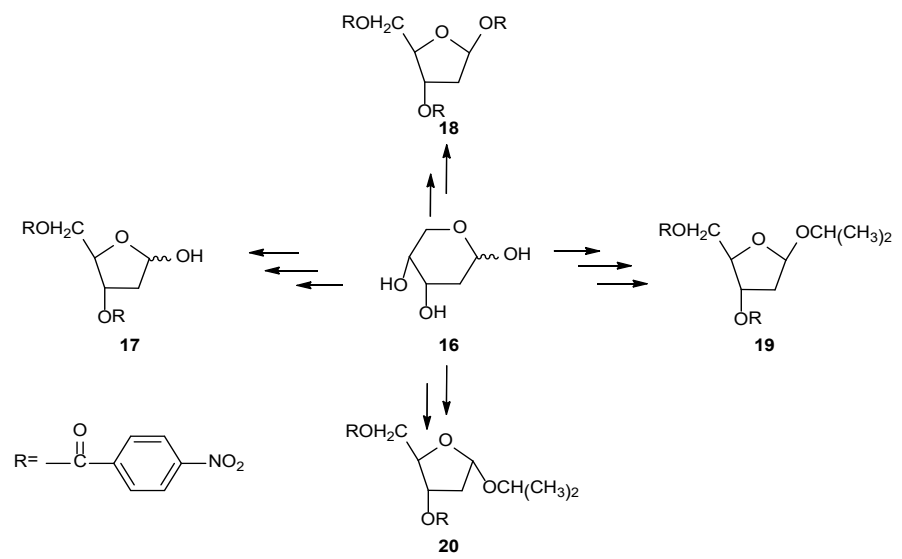

Scheme 6. The synthesis of ribose derivatives (17-20) [30a].

In the same year, Potgieger and Mac Donald made the condensation of benzaldehyde with D-ribose di- $n$-propyl ditioacetal and then converted to dimethyl acetals for the corresponding substituted D-riboses (21) and ribitols (22) (Scheme 7) [30b]. Fox et al succeeded in synthesizing $2^{\prime}$-deoxycytidine (V) (23) via condensation of 3, 5-di-O-(pchlorobenzoyl)-2-deoxy-D-ribosyl chloride with $A^{\prime}$ acetylcytosine mercury in the same year (Scheme7) [30c].

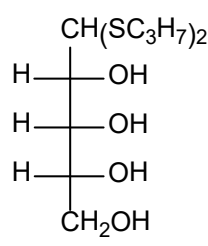

21<smiles>[R]OCC1OC([Hg])OC(CO[R])C1[R9]</smiles>

$$
\begin{aligned}
\mathrm{R}=\mathrm{R}^{\prime} & =-\mathrm{CH}_{3} \mathrm{CO}, \\
\mathrm{R} & =\mathrm{R}^{\prime}=-\mathrm{H}, \\
\mathrm{R} & =\mathrm{H}, \mathrm{R}^{\prime}=\mathrm{C}_{6} \mathrm{H}_{5} \mathrm{CO}
\end{aligned}
$$

22

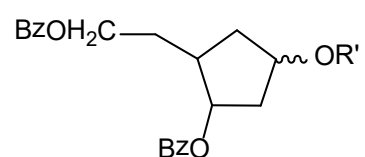

$\mathrm{R}=-\mathrm{COCH}_{3},-\mathrm{COC}_{6} \mathrm{H}_{5}$

23
Scheme 7. The synthesis of substituted ribose (21), ribitol (22) and 2 '-deoxycytidine $(23)[30 b, c]$.

The following year, Mac Donald and Fletcher succeeded in synthesizing anomeric 2-deoxy-D-ribofuranose-1phosphates by condensation with 2-deoxy-3, 5-di-p-toluoylD-ribosyl chloride in the presence of disilver phosphate [31a]. In the same year, Serfontein and Jordaan synthesized the D-ribose cyclic nitrogen mustard phosphamide ester, which has potent cancer growth inhibitory properties [31b].
The synthesis of 4-thio-D- and -L-ribofuranose and the corresponding adenine nucleosides $(24,25)$ from L-lyxose was successfully performed by Reist et al in 1964 (Scheme 8) [32a]. Moffatt succeeded in synthesizing nucleoside5 'triphosphates (26) using pyridine as a solvent (Scheme 8) [32b]. In four separate studies, the synthesis of di amino sugaroses was carried out by Baker and Neilson in the same year [32c]. Nucleosides containing the 1b-D-arabinofuranosyl moiety showed interesting biological properties.Underwood et al worked on cytosine arabinoside and other nucleosides in Herpes virus infections [32d].

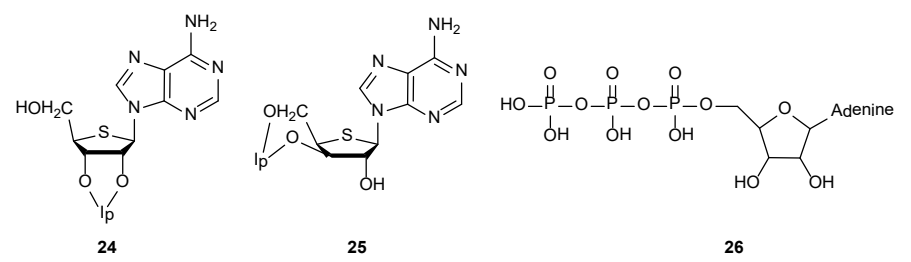

Scheme 8 . The synthesis of thio-ribofuranose $(24,25)$ and nucleoside-5'triphosphates (26) [32a,b].

Leonard and Laursen synthesized 3-b-DRibofuranosyladenine and (3-b-D-ribofuranosyladenine)-5'phosphate by alkylation of adenine with bromo tribenzoylribofuranose and debenzoylation with methanolic ammonia in 1965 [33a]. In the same year, they succeeded in synthesizing adenosine diphosphate, adenosine triphosphate, and nicotinamide-adenine dinucleotide analogs from 3-b-Dribofuranosyladenine [33b]. Murray and Prokop synthesized of 9-(3-deoxyyaldofuanosyl) adenies from 3-deoxy-D-glucose with some reactions such as benzoylation, acetolysis, halogenation, periodate oxidation, and borohydride reduction in 1965 [33c].

In 1965, Ferrier and Prasad succeeded in synthesing of 3- and 2,4-substituted ribose derivatives and wrote about the nature of phenylboronates of methyl $b$-L-arabino-, methyl a-D-lyxo-, and methyl b-D-ribo-pyranoside [34a]. In the same year, Baker and Hullar conducted two different studies oncis-2, 3-diamino sugar synthesis and the influence of neighboring groups [34b]. In the same year, Baker and Buss synthesized in a different study a-sulfonyloxy oxo sugar and 2(3)-acylamino-3(2)-oxopyranosyl [34c].

Fox and et al studied the reaction of the 5'-O-trityl derivative of uridine (27) with thiocarbonyldiimidazole. In the result of the reaction 2, 2'-anhydro-1-(b-D-arabinofuranosyl) urasile (28) occurred in high yields (Scheme 9) [35a]. Leonard and Carraway synthesized 5-amino-5-deoxyribose and its nucleosidederivativefrom 1-benzyl-5-cyano-4-ethoxymethylene amino imidazole cyclization. [35b] Reist et al. prepared D-ribose and L-lyxose derivatives using toslation, hydrolysis and benzoylation reactions beginning with L-ribose in 1966 [36c]. In the same year, Baker and Buss succeeded in developing new branch-chain amino sugar types for methyl 2-benzamido-4, 6-O-benzylidene-2-deoxy-tetrahydrofuranoside, methyl 2-benzamido-4, 6-O-Deoxy-3-3C-methyl-[a]-Dallopyranoside [35d]. Lerner and Kohn also worked on the synthesis of 9-D-Mannofuranosyladenin from D-mannose [35e]. 


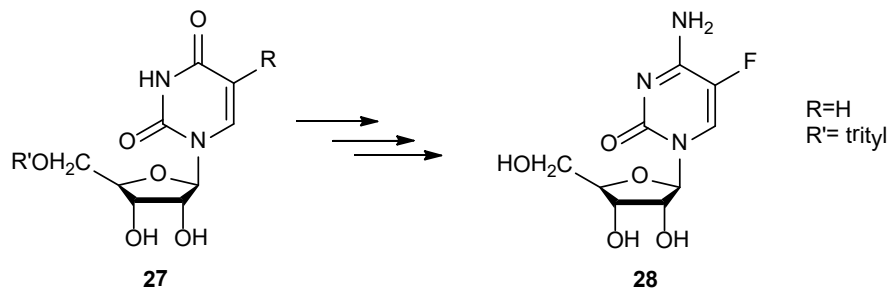

Scheme 9 . The synthesis of $2,2^{\prime}$-anhydro-1( $\beta$-D-arabinofuranosyl) urasile (28) [35a].

In 1967, Ali et al described the reaction of methyl $\beta$-dribopyranoside with sulfuryl chloride and pyridinium chloride in an article [36a]. The reaction of D-ribose with sulfuryl chloride yielded D-ribopyranosyl chloride tri (chlorosulfate).In the same year, Onodera et al. achieved the synthesis of 9-a-Dribofuranosyladenine [36b]. Eckstein and Gindl explained the synthesis of thymidine 5 '-triphosphate and uridine 5 '-di- and triphosphate using triimidazolyl-1-phosphynsulfide [36c].

In 1968, Fukami et al reported the synthesis of 5-deoxy$( \pm)$-allose derivatives and 4-deoxy-( \pm )-ribose from myoinositol [37a]. Lerner et al succeeded in synthesizing of 9-b-DGulofuranosyladenine and 9-a-L-Lyxofuranosyladenin by means of Isopropylidene sugar derivatives [37b]. 3-Amino-3deoxy-D-ribose and D-ribose (29) were synthesized from D-xylose 1, 2-O-Isopropylidene-5-O-triphenylmethyl-a-Dxylofuranos derivatives by Sowain the same year (Scheme 10) [37c].

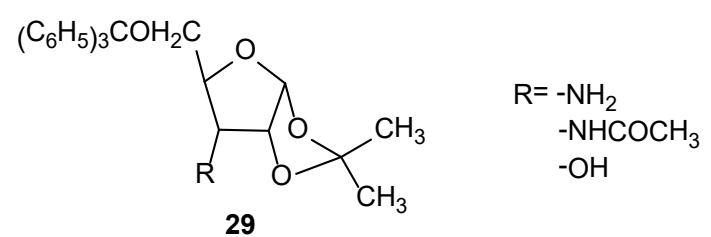

Scheme 10. The synthesis of amino-3-deoxy-D-ribose derivatives [37c].

O-isopropylidene derivative of D-ribose diethyl dithioacetal was synthesized by Lance et al. using copper sulfate as a catalyst in 1969 [38a]. Lerner also realized the synthesis of 9-a- and 9-b-L-erythrofuranosyladenine $(30,31)$ via isopropylidene sugar derivatives (Scheme 11) [38b].

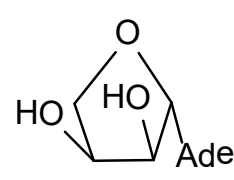

30

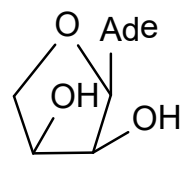

31
Scheme 11. The synthesis of $9-\alpha-$ and $9-\alpha-L-$ erythrofuranosyladenine [38b].

Follman and Hogenkamp synthesized ${ }^{18} \mathrm{O}$-containing ribose and adenine nucleotides, and the isotope position in hydroxyl functions was confirmed by mass spectrometry in 1970 [39a]. Niedballa also provided the synthesis of pyrimidine nucleoside [39b]. In1971, Ryan et al. succeeded in synthesizing furanose and pyranose 2-thio-D-ribose derivatives (32) from the corresponding S-alkyl-1-thio-a-arabinoside 2-O-mesylate (Scheme12) [40].

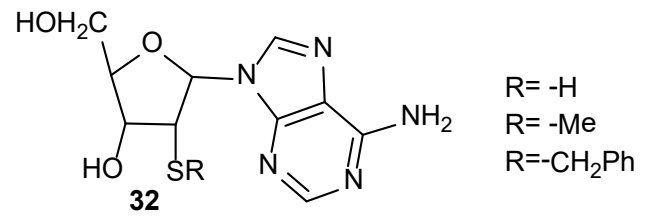

Scheme 12. The synthesis of 2-thio-D-ribose (32) [40].

In 1972, Lerner synthesized 9-(6-Deoxy-b-L-glucopyranosyl) adenine, 9-(5, 6-dideoxyxylo-hex-5-enofuranosyl) adenine, 9-b-L-gulofuranosyladenine, 4', 5'-unsaturated hexofuranosyl nucleoside in three different studies [41a]. Witkowski et al obtained1-b-D-Ribofuranosyl-1,2,4-triazole-3-carboxamid (33-36) and related nucleosides and then researched the antiviral activity of them (Scheme 13) [41b].

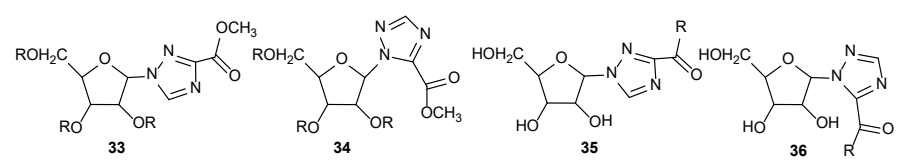

Scheme 13. The synthesis of 1-b-D-Ribofuranosyl-1,2,4-triazole3-carboxamid (33-36) [41b].

In 1973, 3-C-(dimethoxy) phosphinyl-1,2:5,6-di-Oisopropylidene- $\alpha-D$-allofuranose was obtained from the reaction of 1,2:5,6-di-O-isopropylidene- $\alpha$-D-ribo-hexofuranos-3-ulose with dimethyl phosphite by Evely et al [42a]. In the same year, Rabelo et al obtained 5-seleno-D-ribose derivatives from methyl 2, 3-O-isopropylidene-D-ribofuranoside under various reaction conditions as reaction time, solvent and catalyst [42b]. Lerner worked on the synthesis and reexamination of the structure of 9-(6-deoxy-.alpha.-L-mannofuranosyl) adenine [42c].

Niedballa and Vorbrügg by noticed the pyrimidine nucleoside synthesis containing silylated hydroxy-, amino-, and mercapto pyrimidines using Friedel-Crafts catalysts in excellent yields in 1974 [43a]. The synthesis of D-ribose-5-phosphonate and -vinyl phosphate analogs (37-39) was carried out by Hampton et al in the same year (Scheme 14) [43b]. Rabelo and Es synthesized selenoxides of $D$-xylose and $D$-ribose derivatives (40-43) (Scheme 14) [43c].

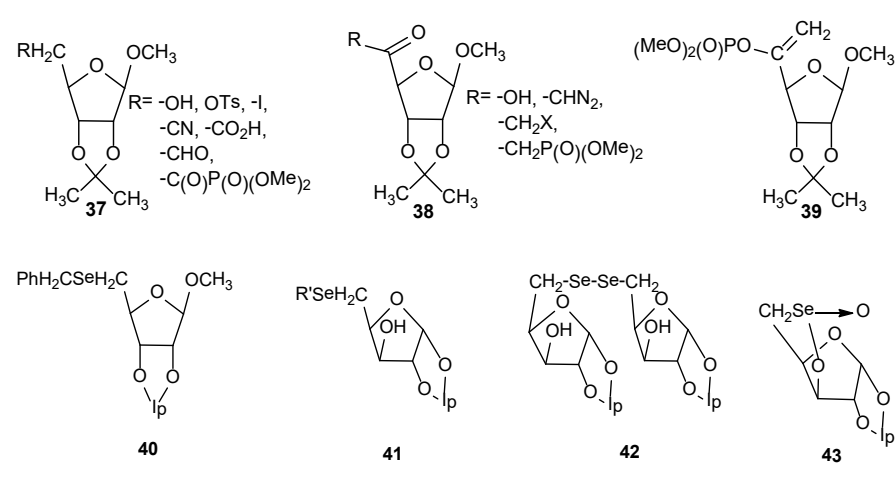

Scheme 14. Phosphonate, vinyl phosphate and selenoides analogs of ribose $[43 b, c]$.

The synthesis of 9-a-D-Idofuranosyladenine (45) starting from D-glucoseand N-(2, 3, 5-Tri-O-acetyl-D-ribofuranosyl) maleimide (44) was performed by Lerner in 1975 (Scheme 15) [44a]. Schwartz and Lerner [44b] succeeded in synthesizing $\mathrm{N}$-(2, 3, \%-tri-O-acetyl-D-ribofuranosyl) maleimide (47) with $25 \%$ yield using $\mathrm{N}^{4}$-acetylcytosine as base (Scheme 15 ). 

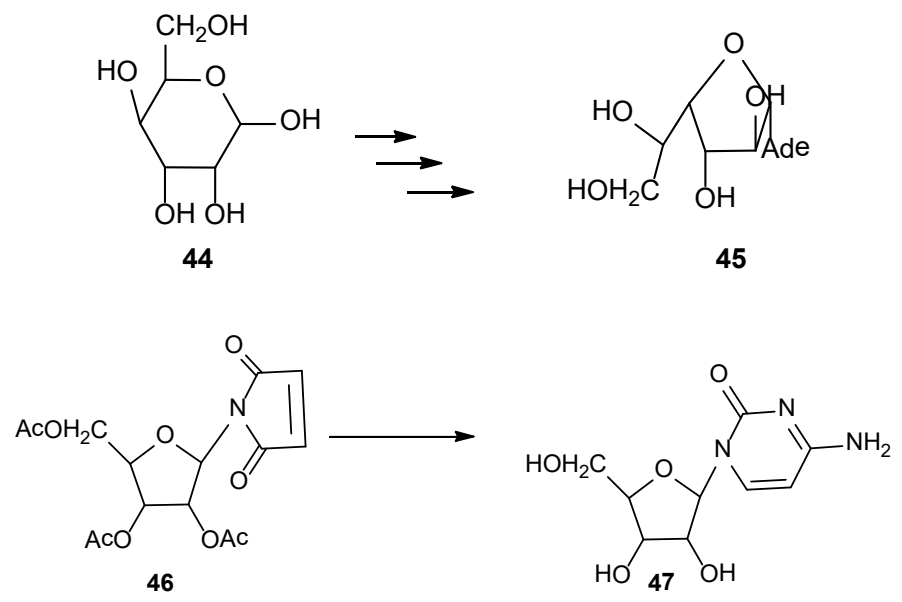

Scheme15. The synthesis of nucleoside 45 and 47 [44a,b].

In 1976, Es succeded in synthesizing of O-methyl derivatives of 4-thiopento furanosides and an hydropentosesin 1976 [45a]. Lerner also developed a method for the synthesis of adenine nucleosides $(48,49)$ from 6 -deoxyhexofuranoses (Scheme 16) [45b]. Niedballa and Vorbrüggen examined the effect of groups linked at positions 5 and 6 with silylated urasil in nucleoside synthesis (Scheme 16) [45c].

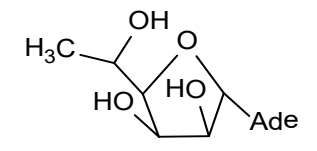

48

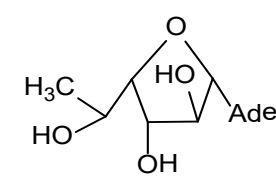

49
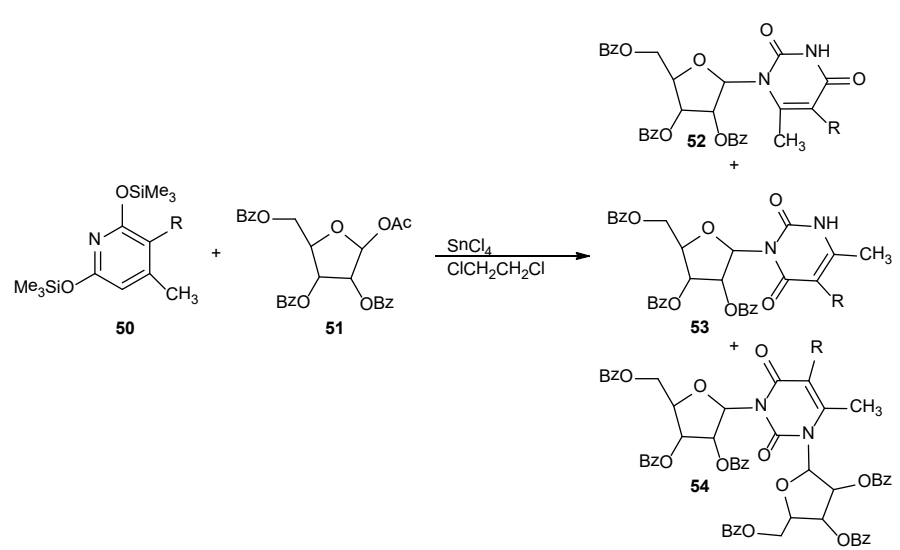

Scheme 16. Uracil nucleoside synthesis [45b,c].

In 1977, Blumberg et al studied selenium derivatives of L-arabinose, D-ribose, and D-xylose [46a]. Benzyl 2,3,4-tri-Oacetyl-1,5-diseleno-D-xylopyranoside, benzyl 2,3,4-tri-Oacetyl-1,5-diseleno-D-ribopyranoside, and benzyl 2,3,4-tri-Oacetyl-1,5-diseleno-D-arabinopyranoside which were synthesized at the end of the study [46a]. Es synthesized 2, 5- an hydropentose dibenzyl dithioacetates from pentose dibenzyl dithioacetates using D-ribose and D-xylose in acid solution (Scheme 17) [46b].
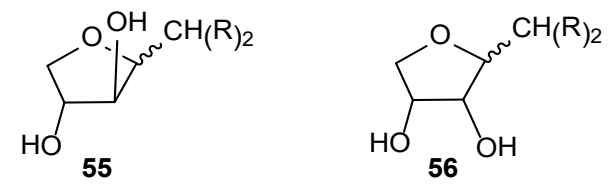

Scheme 17. The synthesis of ribose 55 and 56.
In 1978, Schaeffer et al synthesized a series of nucleoside analogs, suggesting that 9-(2-hydroxy-ethoxymethyl) guanine has significant antiviral activity in animal models of herpes virus infections [47a]. Lerner synthesized enantiomeric forms of 9-(5-deoxy-a-D-arabinofuranosyl) adenine (57) from D-ribose, 9-(6-Deoxyhexofuranosyl) adenine (58) from L-Rhamnose and 9-(5, 6-dideoxy-b-D-ribo-hex-5-enofuranosyl) adenine (59) from D-allose at various stages (Scheme 18) [47b]. Ueda et al succeeded in synthesizing 6-thioguanine and 2, 6-diaminopurine nucleosides (60) and nucleotides from adenine (Scheme 18) [47c].

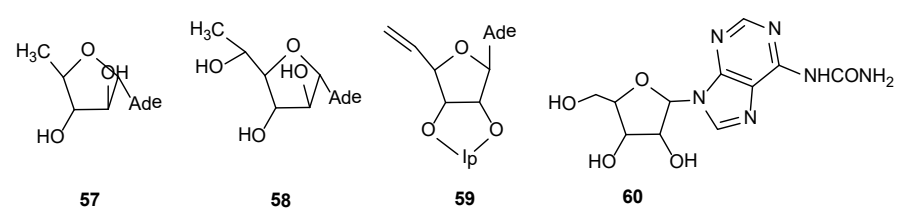

Scheme18. Nucleoside derivatives (57-60).

Lerner performed the synthesis of 9-(5, 6-dideoxy-b-Derythro-hex-4-enofuranosyl) adenine (61-64) $\mathrm{E}$ and $\mathrm{Z}$ isomers starting from 5, 6-dideoxy-5-iodo-2, 3-O-isopropylidene-bD-allofuranoside and 5,6-dideoxy-5-iodo-2,3-O-isopropylidenea-L-talofuranoside (Scheme 19) in 1979 [48a]. Quinazoline nucleosides were synthesized by Ferris et al. from ribose and antranilonitrile [48b]. Keyser et al disclosed a method for preparing alkylated acyclic nucleoside analogs using iodomethyl ether and thioether by reacting 1, 3-dioxolane and 1, 3-oxathiolane with trimethylsilyl iodide [48c].<smiles>CC=C1O[C@H](C)C1O</smiles>

61<smiles>CC=C1O[C@H]2OPOC12</smiles>

62

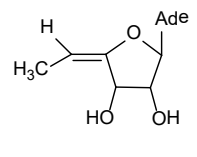

63<smiles>CC=C1O[C@H]2OPOC12</smiles>

64
Scheme 19. Nucleoside derivatives (61-64)

In 1980, Sun and Fraser-Reid developed a plan for the synthesis of analogs of the nactin family $(66,68)$ from the D-ribose derivative (Scheme 20) [49a]. Barrio et al prepared a direct method for the synthesis of 2-hydroxyethoxymethyl derivatives of guanine, adenine and cytosine [49b].

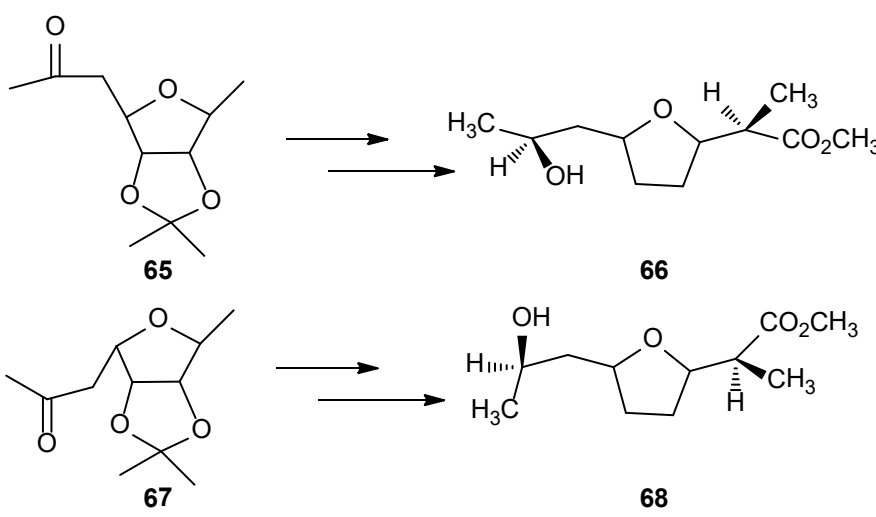

Scheme 20. Ribose derivatives $(66,68)$.

In 1981, Khadem and Nelson explained the synthesis of 6-deoxy-D-allo- and -L-talo-furanosyl bromide derivatives used for nucleoside synthesis [50a]. Daskalov et al synthesized $\mathrm{O}^{6}$-substituted Guanosine derivatives with phosphoryl, 
phosphinothioyl, arylsulfonyl and silyl halides using 4-(dimethylamino) pyridine as catalyst in good yield [50b]. In Scheme 21 only a few examples (69-74) are shown.Vor bruggen obtained new Lewis acids $\left[\left(\mathrm{CH}_{3}\right)_{3} \mathrm{SiOSO}_{2} \mathrm{CF}_{3^{\prime}}\left(\mathrm{CH}_{3}\right)_{5} \mathrm{SiOSO}_{2} \mathrm{C}_{4} \mathrm{~F}_{9}\right.$ and $\left.\left(\mathrm{CH}_{3}\right)_{3} \mathrm{SiClO}_{4}\right]$, which are highly selective and efficient Friedel-Crafts catalysts for the synthesis of nucleoside silylated heterocycles and peracylated sugars [50c].
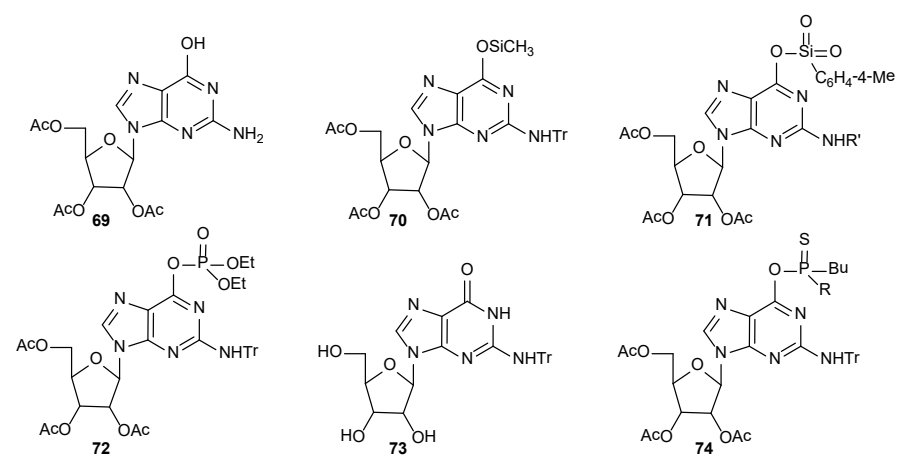

Scheme 21. Nucleoside derivatives (69-74).

In 1982, Mukaiyama et al described an efficient method for stereo selective synthesis of 2-amino-2-deoxy-D-arabino and D-ribose [51a]. Pasque et al conducted a study titled "Riboseenhanced myocardial recovery following ischemia in the isolated working rat heart"and explained ribose infusion as a biochemically Iplausible method to ameliorate postischemic myocardial ATP before and after ischemia [51b]. Sims et al synthesized poly (adenosinediphosphoribose) polymerase and explained how the poly (adenosinediphosphoribose) polymerase was inhibited by a six-membered aromatic ring compounds containing a carboxamide group and purine analogues [51c].

In 1983, Hiratsuka synthesized ribose modified, fluorescent adenine and guanine nucleoside and nucleotide derivatives in aqueous solution at mild $\mathrm{pH}$ and temperature [52a]. Robins and Parker explained the transformations of D-ribose to 3, 4-O-isopropylidene-2, 5-anhydro-D-allose, which was synthesized previously as a racemate and used to prepare C-nucleosides (Scheme 22) [52b].

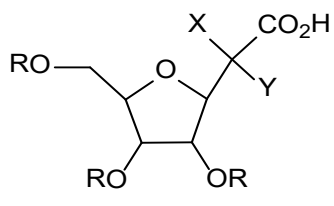

75

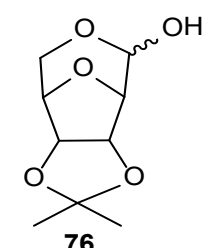

Scheme 22. The transformations of D-ribose 3,

4-0-isopropylidene-2, 5-anhydro-D-allose.

In 1984, Forrest and Schmist synthesized 4-amino-4deoxy- $D$, L-ribose derivatives [53a]. Sato described the stereo controlled total synthesis and various biological properties of C-nucleosides (77) with different R groups (Scheme 23) [53b].

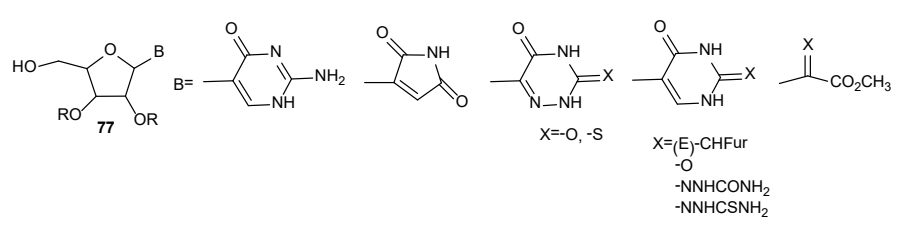

Scheme 23. The stero controlled total synthesis of C-nucleoside (77).
In 1985, isopropylidenation of $D$-ribose diethyl ditioacetal and ribitol and the synthesis of $\alpha$ and $\beta$ - D-ribofuranosylethyne were carried out by Aslani-Shotorbani et al [54a]. Yamamoto et al performed the stereo selective synthesis of 2-amino-2deoxy-D-arabinose and 2-deoxy-D-ribose [54b]. Berger et al developed a new strategy for cancer chemotherapy using synthetic " $\mathrm{C}$ " nucleoside analogs [54c].

In 1986, Hughes and Wood disclosed the sulfur addition in displacement reactions of the sulfonate esters of 5-thio-Dribose and 5-thio-D-xylose derivatives [55a]. Schmidt also did research on natural product synthesis, including ribose derivatives (78) (Scheme 24) [55b].

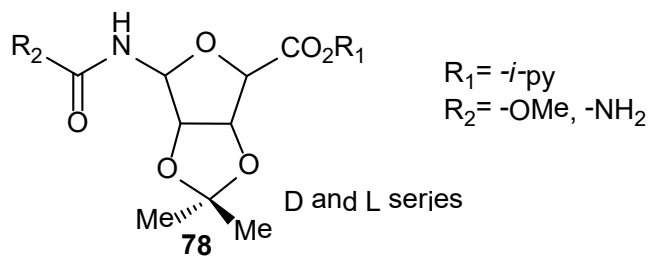

Scheme 24. The synthesis of ribose derivative 78 .

In 1987, Mc Elwain and Pollack found deoxyribononomonucleoside kinase activity in the first report of deoxyribonucleoside kinase activity dependent on PPi in Acholeplasma and Mycoplasma species [56a]. Beigelman et al prepared the synthesis of 2'-C-methylnucleosides (3-O-benzyl-1,2-O-isopropylidene-3-C-methyl- $\alpha$-Dallofuranose and 1,2,3-tri-O-acetyl-2-C-methyl-5-O-pmethylbenzoyl-d-ribofuranose, 2-C-hydroxymethy $\quad \mathrm{I}, \quad 2$, 3-O-isopropylidene-5-O-trityl-D-ribofuranose) starting from D-glucose and D-ribose [56b].

In 1988, Mc Elwain et al isolated the purine nucleoside phosphorylase (PNP) from a cytoplasmic fraction of Acholeplasma laidlawii B-PG9 and described its activity using a gel green affinity chromatography [57a]. Shapiro showed the prebiotic availability of D-ribose as a subunit in his article [57b]. Hennen et al explained the acylation and deacylation reaction of the furanose and pyranose derivatives with lipase enzyme [57c]. Wagner et al performed the synthesis of methyl 5 -bromo-5-deoxy-2, 3-O-isopropylidene- $\beta$ - Dand- $\beta$-L-ribofuranoside from (-)-(1R,2S,4R)-2-exo-cyanoxabicylo[2.2.1] hept-5-en-endo,-yl(1'S)-camphanate and (+)-(1S,2R,4S)-2-exo-cyano-7-oxabicyclo [2.2.1] hept-5-en-2endo-yl( $\left.1^{\prime} R\right)$-camphanate in 5 steps and with a total yield of 28\% [57d]. A simple and stereo controlled 2-deoxy-2, 2-difluoro-D-ribose (79) and 2-deoxy-2, 2-difluoro-Dribofuranosyl nucleosides synthesis (79-81) in the design and synthesis of potential nucleosides as anticancer and or antiviral agents was performed by Hertel et al (Scheme 25) [57e].
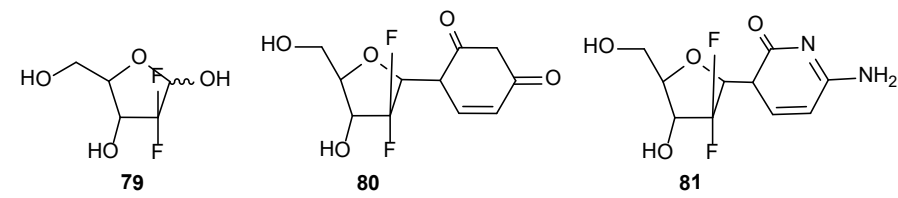

Scheme 25. The synthesis of 2-deoxy-2, 2-difluoro-D-ribose (79) and 2-deoxy-2, 2-difluoro-D-ribofuranosyl nucleosides $(80,81)$. 
In 1989, Herdewijn et al described the use of diethylaminosulfur trifluoride (DAST) as a fluorinating agent in the nucleoside field [58a]. Hennen and Wong reported a method be applicable to the enzymatic ribosylation of purine analogs using 7-methylguanosine and 7-methylinosineh [58b]. Ludwig and Eckstein performed a facile synthesis of the $5^{\prime}-O$-(L-thiotriphosphates) and showed that the 5 '-triphosphates of eight common substances could be readily used for nucleoside synthesis (Scheme 26) [58c]. Yokoyama and Yamada succeeded in synthesizing spiro and bicyclic nucleosides from ribose nitrile oxide and dimethyl acetylenedicarboxylate (Scheme 26) [58d].

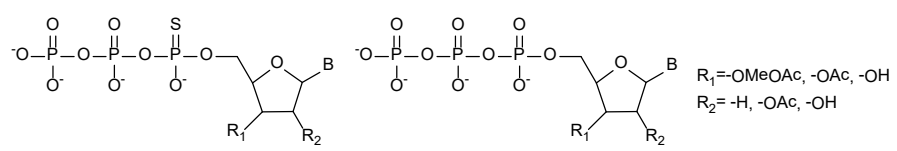

82

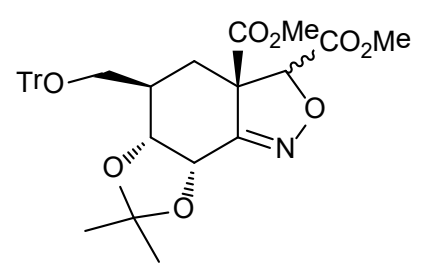

84
83

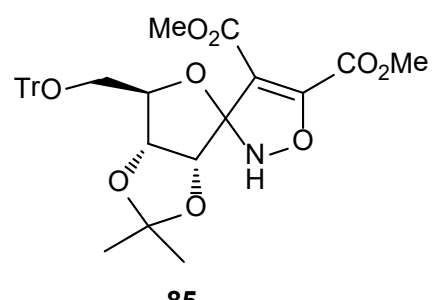

85
Scheme 26. The synthesis of monocyclic $(82,83)$ and bicyclic nucleotides $(84,85)$

In 1990, Hutchinson prepared a review on the synthesis of antiviral nucleosides because new antiviral agents are needed worldwide [59].

In 1991, Musicki and Widlanski reported the synthesis of sulfonate analogues of adenine, cytidine and guanine monophosphates as well as the synthesis of ribose 3-sulfonate, sulfonyl disaccharides and dinucleotides (Scheme 27) [60].

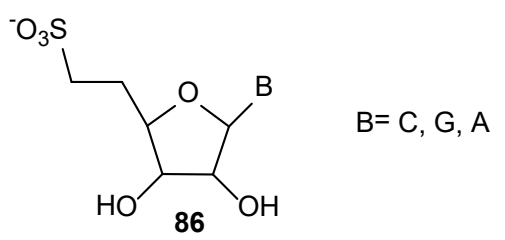

Scheme 27. The synthesis of sulfonate analogues 86 of adenine, cytidine and guanine monophosphates.

Beach et al studied the synthesis of enantiomerically pure (2'R, 5'S)-(-)-1-[2-(hydroxymethyl) oxathiolan-5-yl] cytosine and worked on antiviral activities against hepatitis $B$ virus (HBV) and human Immuno deficiency virus (HIV) in 1992 (Scheme 28) [61].

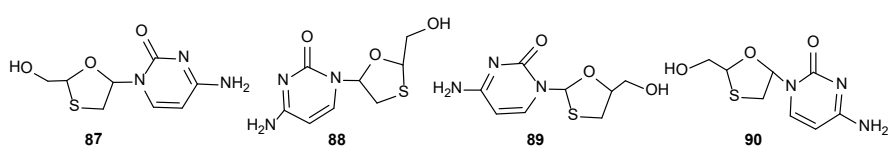

Scheme 28. The synthesis of enantiomerically pure nucleosides (87-90).

Matsuda et al synthesized 2'deoxy-(2'-C-substituted) cytidines, examined the antitumor activities of synthesized products and showed the anticancer properties of the molecules [62a]. Munier et al succeeded in synthesizing 5-deoxy-5, 5, 5-trifluoro-D and L-ribose and lyxose 93 derivatives from lactones 91 using $\mathrm{CF}_{3} \mathrm{SiMe}_{3}$ (Scheme 29) [62b]. Waga et al prepared appropriately conserved 4'-C-methyl-D-ribo- and xylo-pentofuranoses and their condensation reactions with nucleobases (Scheme 29) [62c].
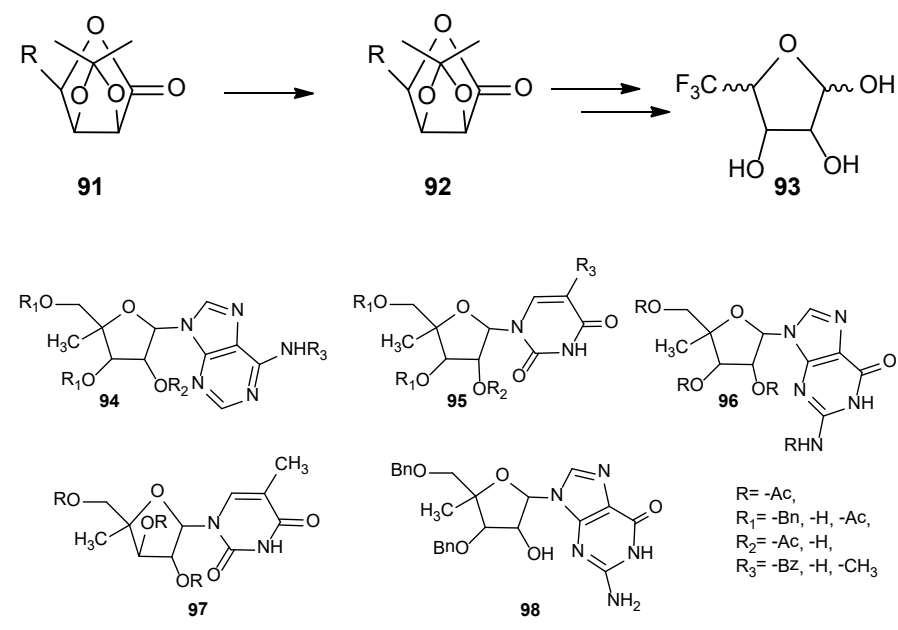

Scheme 29. The synthesis of ribose and nucleosides (94-98).

Ruff et al described a novel synthesis of chiral 2, 3-dideoxy nucleosides and their carbocyclic anologues starting from chiral cyclobutanone using a photo chemical ring-extension and a carbon ring extension in 1994 [63a]. Kolb et al determined thermodynamic and kinetic parameters for the urine reaction to be synthesized under prebiotic conditions using ribose from bureaucratic and hydrazine (Scheme 30) [63b].<smiles>O=c1[nH]c(=O)n(C2OC(CO)C(O)C2O)[nH]1</smiles><smiles>O=c1[nH]c(=O)n(C2OC(CO)C(O)C2O)[nH]1</smiles>

$\beta$-furanoside $(\beta-F)$

Scheme 30 . The synthesis of a-and $\beta$-furanoside $(99,100)$.

In 1995, Prasad et al synthesized tri-O-acyl 2-deoxy-Dribofuranose from 2-deoxy-D-ribose by a one-pot procedure in high yields and decribed the conversation to 2'-deoxynucleosides using monoacylations catalyzed by regioselective lipase (Scheme 31) [64].
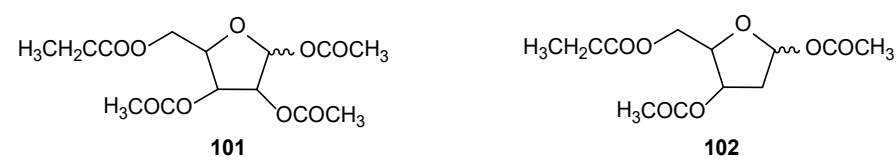

Scheme 31. The synthesis of tri-O-acyl 2-deoxy-D-ribofuranose 101 and 102.

In 1996, Sekine provided $D-\left[5-{ }^{13} C\right]$ ribosylation from D-ribose to a $\left[5^{\prime}-{ }^{13} \mathrm{C}\right]$ nucleoside, with an 8 -step total yield of $70 \%$, by coupling reaction [65].

In 1997, synthesis of 9-(2-O- $\beta$-D-ribofbranosyl- $\beta$ -D-ribofuranosyl) adenine, guanine- and the pyrimidine 
analogs (cytosine, thymine and uracil base) was performed by Mikhailov et al in a high yield [66a]. Choi et al worked on the synthesis of sulfated deoxy-ribofuranans with selective antiAIDS virus activity by ring-opening copolymerization of 1 , 4-anhydro ribose derivatives [66b].

In 1998, various adenosine analogues were tested by Zwart et al on adenosine $A_{2 B}$ receptor and found that the $5^{\prime}-\mathrm{N}$-substituted carboxamidoadenosines were the strongest [67a]. Volpini et al synthesized deoxyribose nucleosides by coupling chloro purines with D-ribose derivatives and examined some of biological properties of the synthesized nucleosides [67b]. Shuto et al. performed the reaction with an 8-bromo-substitution of $\mathrm{N}$-1-(carbocyclic-ribosyl) inosine $5^{\prime}$, $6^{\prime \prime}$-diphosphate 103 to obtain cyclic IDP-carbocyclic-ribose (Scheme 32) [67c]. Izawa and Shiragami developed enzymatic transglycosylation, chemical transpurination, and alkylauon for stavudine, acyclovir, ganciclovir, penciclovir and famciclovir [67d].

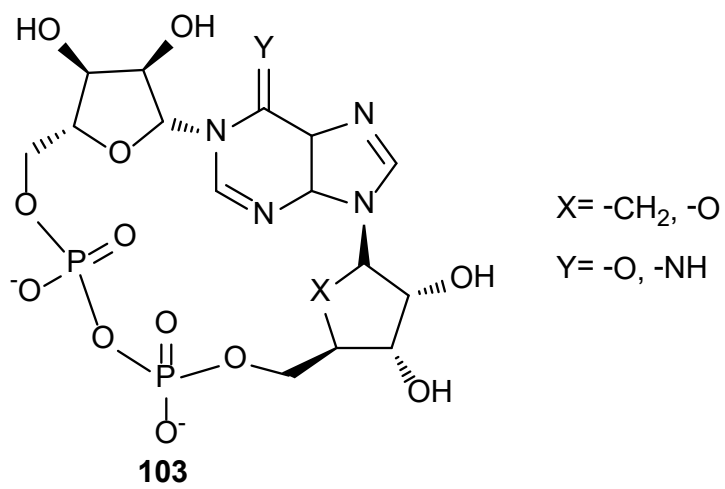

Scheme 32. The synthesis of $\mathrm{N}$-1-(carbocyclic-ribosyl) inosine 5, 6"-diphosphate 103.

Also in 1998, trisaccharide nucleosides were obtained in good yield during synthesis of disaccharide nucleosides in the Mikhailov et al study [67e]. The use of 2', 3'-O-isopropylidene was observed in this study which inhibited the formation of trisaccharide nucleosides during disaccharide synthesis. Thus the yield of disaccharide nucleosides was increased (Scheme 33).
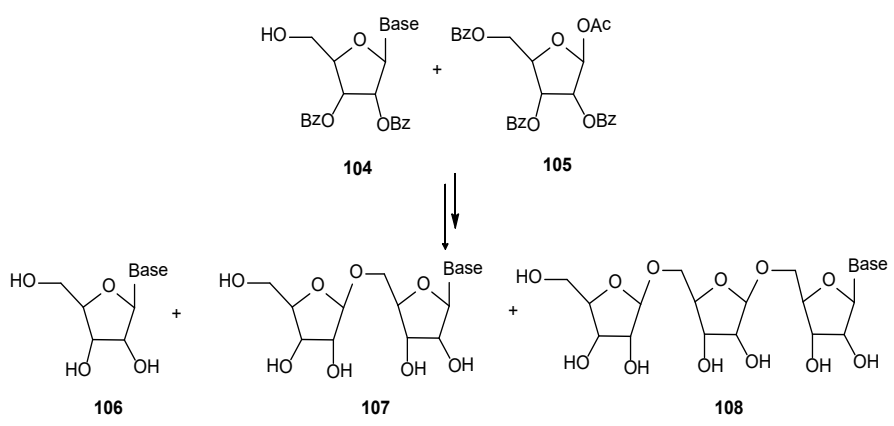

Scheme 33. The synthesis of mono-, di- and trisaccharide (106-108).

The same year, Efimtseva et al conducted a research on disaccharide nucleosides and their enzymatic properties and showed that oligonucleotides with reactive dialdehyde groups are effective against polymerases and restriction enzymes [67f]. Griffin et al realized the synthesis of exoglyclas including ribose derivatives (Scheme 34) [67g].

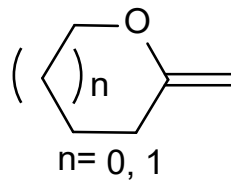

109

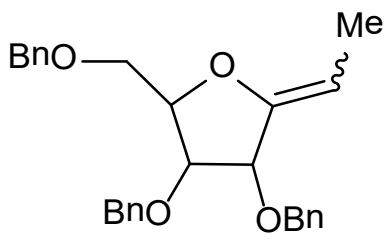

110
Scheme 34. The synthesis of ribose derivative 110 .

In 1999, Vorbrüggen and Ruh-Pohlenz prepared a chapter with the synthesis of nucleosides (e.g.the formation of $\mathrm{N}$-glycosides of heterocyclic nitrogen-based sugars such as D-ribose or 2-deoxy-D-ribose) [68a]. Mc Ewan studied the synthesis and biological activity of ribose- 5 '-carbamate derivatives of vitamin $B_{12}[68 \mathrm{~b}]$. As a result, it was found that Libose carbamate derivatives have similar affinity for intrinsic factor with vitamin $B_{12}$ e-monocarboxylic acid. Fleetwood and Hughes succeeded in synthesizing 2, 3-O-isopropylidene-5thio-D-ribose, 5-thio-D-ribose, 1, 4-anhydro-2, 3-O-isopropylidene- $\alpha$ - $d$-ribopyranose and 1, 4-anhydro-2, 3-O-isopropylidene-5-thio- $\alpha$-D-ribopyranose (Scheme 35) [68c].
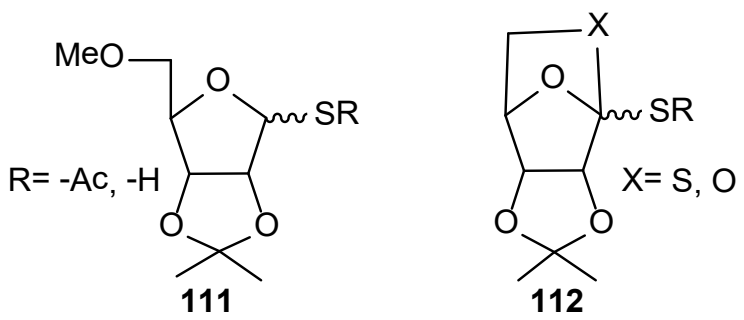

Scheme 35. The synthesis of thio-ribose derivatives 111 and 112.

In 2000, N-Cycloalkyl derivatives of adenosine and 1-deazaadenosine were synthesized by Vittori et al and idenfied their affinities and intrinsic activity in the $A_{1}$ adenosine receptor [69a]. It was seen that all compounds of the ribosebearing series proved to be full agonists, the 1-deaza derivatives showing affinities for the $A_{1}$ receptor were about 10-fold lower than adenosine analogues (Scheme 35) [69a]. Crimmins et al developed a method for the general and efficient synthesis of carbocyclic and hexenopyranosyl nucleosides (113) (Scheme 36) [69b].

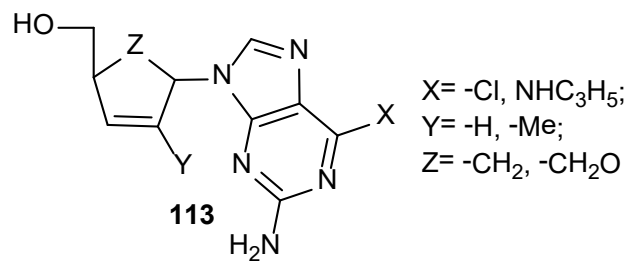

Scheme 36. The synthesis of hexeno pyranosyl (113) nucleoside analogues [69b].

In 2001, Shi et al performed stereospecific synthesis of L-ribose and L-ribosides from D-galactose with a total yield of $57 \%$ in ten steps (Scheme 36) [70a]. Hawkins et al studied the synthesis and fluorescence properties of pteridine adenosine nucleoside analogue 116 and than exhibited unique properties that make them extremely valuable for measuringthe fine events in DNA (Scheme 37) [70b]. 


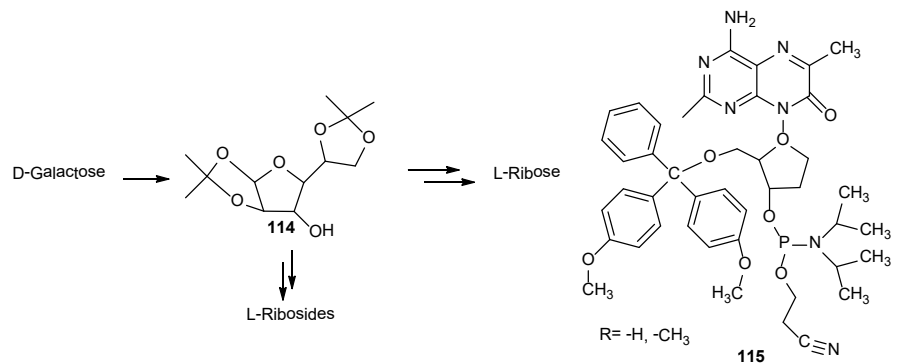

Scheme 37. L-ribose, L-ribosides and pteridine adenosine nucleoside 115

In 2002, Efimtseva and Mikhailov wrote a review on "Disaccharide nucleosides and oligonucleotides on their basis-New tools for the study of enzymes of nucleic acid metabolism" [71a]. Sivets et al synthesized peracylated derivatives of $\beta$-L-ribofuranose from $D$-ribose in 6 steps with a total yield of $50 \%$ [71b]. Moon et al obtained D- and L-cyclopent-2-enone (117 and 118), an intermediate for the synthesis of carbocyclic nucleosides, in six steps starting from D-ribose (Scheme 38) [71c]. Fuentes et al focused on the synthesis of azidonucleosides and fluoronucleosides (119, 120) because they are used in the treatment of diseases such as AIDS [71d]. He succeeded in synthesizing the fluoronucleosides, isothiocyanato C-nucleosides, and thioureylene di-C-nucleosides through cyclic sulfates. Karpeisky et al prepared 2'-Deoxy-2'-N-phthaloyl nucleosides $(121,122)$ from arabino nucleosides by triflate displacement with phthalimide in the presence of DBU (Scheme 38) [71e]. Khudyakov and Fields wrote a book called "Artificial DNA: Methods and Applications" in the same year [71f].<smiles>CC1(C)OC2C=CC(=O)C2O1</smiles>

117
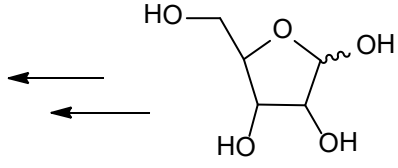

118

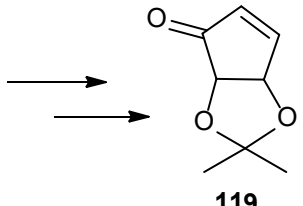

119

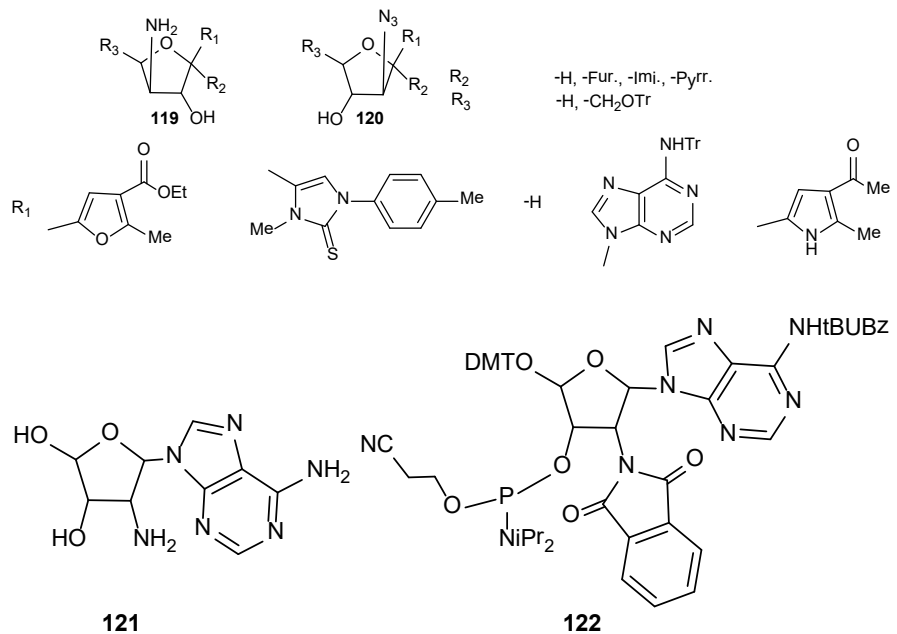

121

122

Scheme 38. The synthesis of ribose and nucleosides

In 2003, Schmidt et al presented a new route an synthesis of $3^{\prime}$ - and $5^{\prime}$-substituted nucleoside derivatives used in the synthesis of oligonucleotide analogues (Scheme 39) [72a]. Kundu et al worked on stereo selective synthesis of deuterated D-ribose derivatives (Scheme 39) [72b].

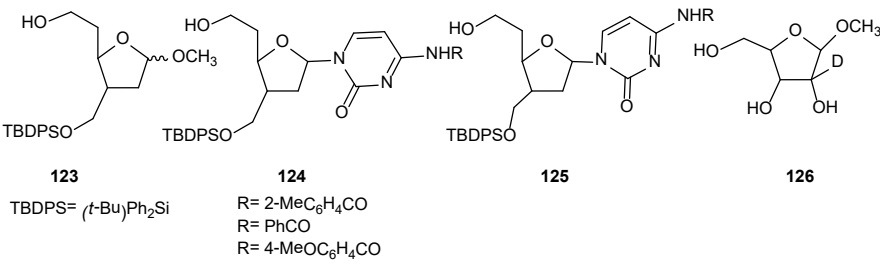

Scheme 39. The synthesis of nucleosides derivatives (123-126)

In 2004, Napoli et al made an important study for the synthesis of 2'-azido, 2'-deoxyuridine, ribose modified nucleosides and nucleic acid analogs, aminoacyl derivatives of 2'-deoxy and 2'-amino-uridine [73a]. Johnson and Widlanski described a methodology for the synthesis of nucleoside phosphates and polyphosphates [73b]. Gu et al performed the synthesis and biological evaluation of N1-[(5"O-phosphorylethoxy) methyl]-5'-O-phosphorylinosine $5^{\prime}$, $5^{\prime \prime}$-cyclicpyrophosphate (cIDPRE) and 8-substituted derivatives (Scheme 40 ) [73c].

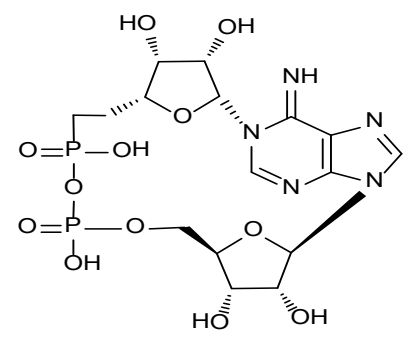

129

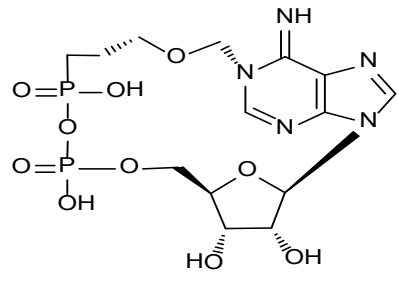

130
Scheme 40. The synthesis of nucleotide derivatives $(129,130)$.

In 2005, Srinhar et al developed a method for the synthesizing epithio and episeleno hexoses and pentoses with good yield (Scheme 41) [74a]. Wagner et al presented a concise synthesis of five new analogues of the second messenger CADPR (cyclic adenosine $5^{\prime}$-diphosphate ribose) using an unusual enzymatic cyclization reaction (Scheme 41) [74b]. Larsen et al examined the $\alpha$-selective $C$-glycosylation reaction for the synthesis of 18 ribose derivatives, 4 of which are different in substitution at $\mathrm{C}-2, \mathrm{C}-3$, and C-4 given in Scheme 41 [74c].
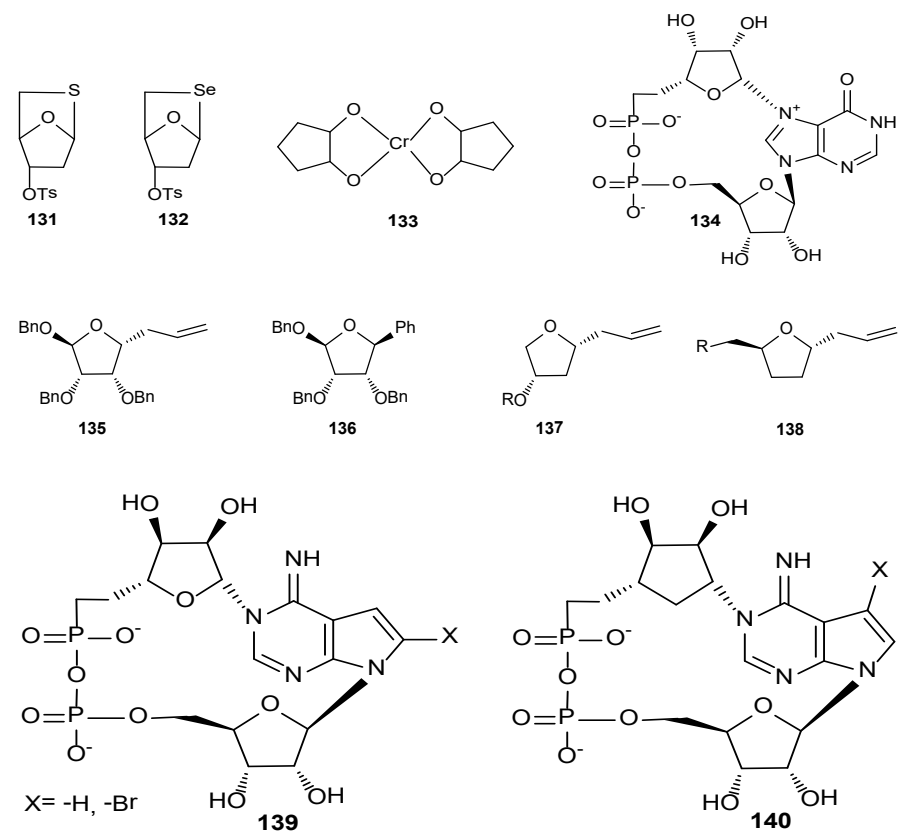

Scheme 41. The different riose, nucleoside, nucleotide derivatives (131-140). 
Romeo et al synthesized phosphonate disoxazolinyl nucleosides from 1, 3-dipolar cyclo addition reaction of nitrile oxides with corresponding vinyl or allyl nucleo bases and examined the cytotoxicity, the anti-HSV activity and the RT-inhibitory activity of the resulting compounds (Scheme 42) [75a]. A synthesis of cyclopentenyl carbocyclic nucleosides from D-ribose was carried out by Cho et al at about 50\% yield (Scheme 42) [75b]. Horhota et al explained the synthesis of glycerol nucleoside triphosphates and substrate activities for enzymatic polymerization (Scheme 42) [75c]. Kosiova et al developed a new approach for coumarin and ferrocene labeled nucleosides prepared with the intermolecular Staudinger ligation (Scheme 42) [75d].<smiles>[B]C1CC(COCC)N([N])O1</smiles>

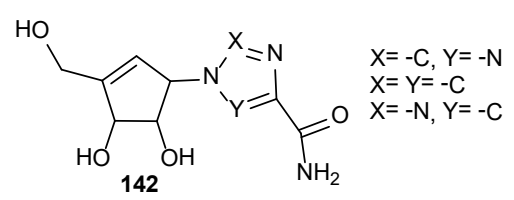

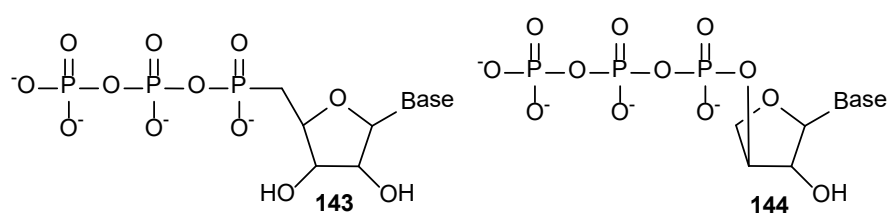

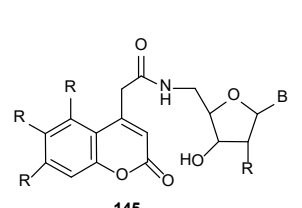<smiles></smiles>

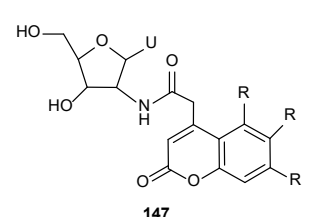

Scheme 42. Ribose derivatives (141-147)

In 2007, Oliviero et al announced the synthesis of nucleobase and ribose solid phase. in good yields. Li et al succeeded in the synthesizing 2'-substituted cyclobutyl nucleosides and worked on anti-HIV effect of the synthesized molecules (Scheme 43) [76a]. Li et al synthesized a series of ribosylated nucleoside phosphonate reverse transcriptase (RT) inhibitors, demonstrated anti-HIV activity and resistance profiles, and the strongest analyst showed [5-(6-amino-purin9-yl)-2,5-dihydro-furan-2-yloxymethyl]-phosphonic acid (d4AP), an HIV EC50= $2.1 \mu \mathrm{M}$ (Scheme 43) [76b]. Mackman synthesized a series of ribose modified nucleoside phosphonate reverse transcriptase (RT) inhibitors, explained their anti-HIV activity and resistance profiles and found that the most potent analog was phosphonic acid (d4AP) [76c].
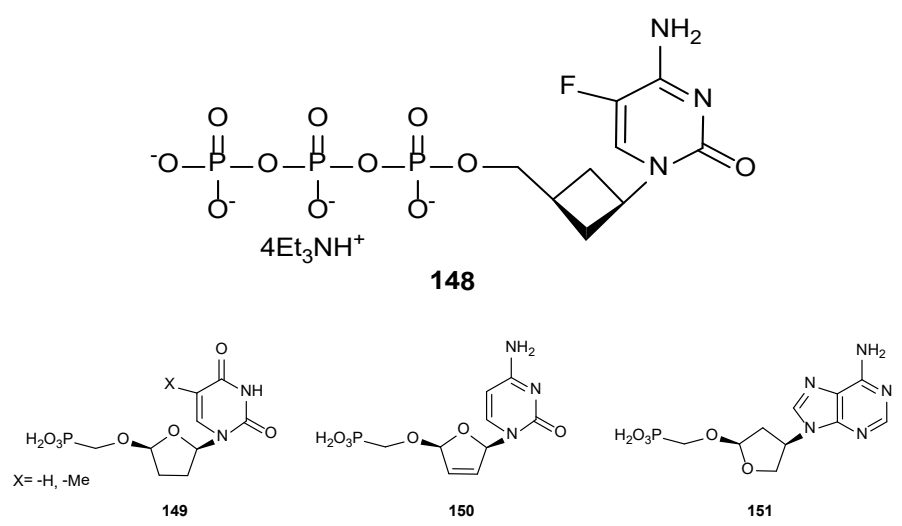

Scheme 43. Nucleoside anologues (148-151).
In 2008, Woodyer succeeded in synthesizing L-ribose as a model target because L-ribose is a potential starting material for many L-nucleoside-based biologically active compounds [77a]. Warnecke and Meier performed a method for the synthesis of nucleoside polyphosphates and nucleoside monophosphate sugars (Scheme 44) [77b]. Kulikova et al reported the first chemical synthesis of 2'-O- $\alpha$-D-ribofuranosyl-nucleosides [77c]. Melman et al disclosed the synthesis of enantiomerically pure (S)-methanocarbaribo uracil nucleoside derivatives to use them as antiviral and P2Y receptor ligands (Scheme 44) $[77 \mathrm{~d}]$.

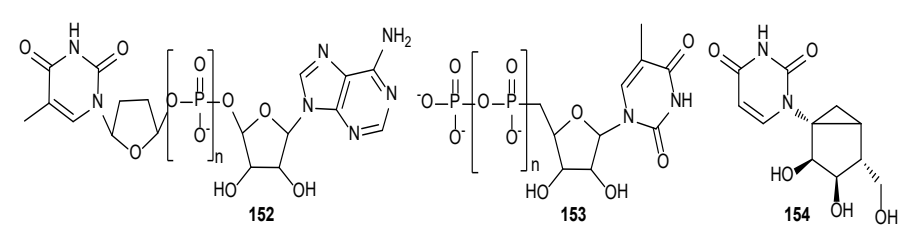

Scheme 44. Nucleoside derivatives (152-154)

A year later, Kulikova et al had developed an efficient and simple synthesis of $5^{\prime}-O-\beta$-D-ribofuranosyl-nucleosides, yielding $74-82 \%$ of this reaction and this reaction was carried out under mild condition $\left(0^{\circ} \mathrm{C}, 7-16 \mathrm{~h}\right)$ [78a]. Cosyn et al examined the synthesis of ribose-based nucleoside 5 '-diphosphates, triphosphates, and related nucleotidesand P2Y receptor activity [78b]. Powner et al the synthesed pyrimidine ribonucleosides in prebiotically plausible condutions [78c]. Okano summarized a review on L-ribose in the therapeutic area and technological progress in preparation [78d]. Helento et al developed a method for the production of L-nucleoside analogues used as antiviral drugs [78e]. The partially purified protein, which has both I-arabinose and L-ribose isomerase activity, was successfully used to convert I-arabinose to I-ribose. In addition, $\alpha-3,5-0$-acetyl-1, 2-O-isopropylidene-D-ribofuranoside was obtained by treating $\beta$-D-ribose tetraacetate with trimethyl aluminum in a high yield by More and Campbell (Scheme46) [78f]. Stalford et al worked on the synthesis of mycobacterial oligo saccharides, investigating neighbouring group participation and addition to oxacarbenium ions in 2009 (Scheme 46) [78g].

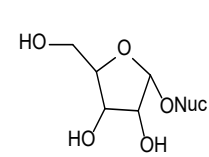

155

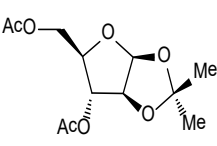

158

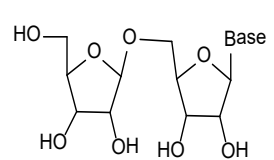

156

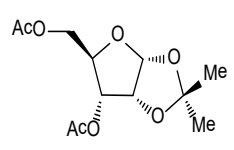

159
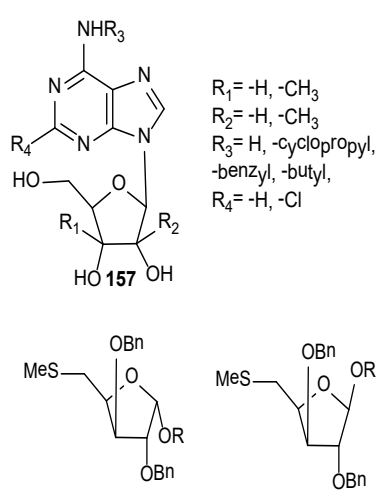

160
$\mathrm{R}_{1}=-\mathrm{H},-\mathrm{CH}_{3}$ $\mathrm{R}_{2}=-\mathrm{H},-\mathrm{CH}_{3}$ $\mathrm{R}_{3}=\mathrm{H},-$-Cyclopropyl, -benzyl, -butyl, $\mathrm{R}_{4}=-\mathrm{H},-\mathrm{Cl}$
Scheme 45. Nucleoside (155-157) and ribose (158-161) derivatives

In 2010, in Ding's work, purine nucleoside phosphorylase and pyrimidine nucleoside phosphorylase were exogenously expressed in Escherichia coli and intact cells were used as a catalyst for biosynthesis of nucleosides (Scheme 47) [79]. 


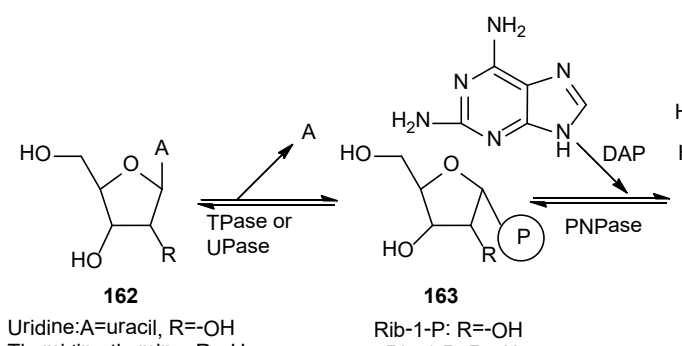

Rib-1-P: $\mathrm{R}=-\mathrm{OH}$ dRib-1-P: $R=-H$

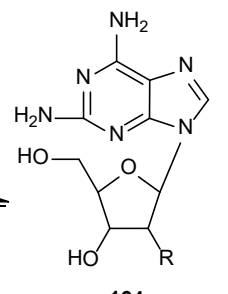

164

DAPR: $\mathrm{R}=-\mathrm{OH}$ DAPdR: $R=-H$

Scheme 47.The enzimatic synthesis nucleosides (164)

Baldoni et al. synthesized per-O-tert-butyldimethylsilyl $\beta$-D-galactofuranosyl isothiocyanate by KSCN with the reaction of per-O-TBS- $\beta$-D-galactofuranosein 2011 [80a]. That same year, Muller and Jacobson conducted a study on the potential of adenosine receptor ligands as new drugs for inflammatory diseases and cancer [80b]. Kulik et al prepared the nucleoside $5^{\prime}-\mathrm{O}$-(N-acyl) phosphoramidates synthesis (Scheme 48) and examined its biological properties (antiviral activity) [80c]. Nucleoside 5 '-triphosphates were synthesized by Caton-Williams using a selective phosphitylating reagent in situ in one pot [80d]. Ghoneim succeeded in synthesizing nucleoside derivatives from L-Rhamnose and 3,4,5-triacetoxy-2methyl-7,9-diaza-1-oxa-spiro [4,5] decane-10-one-8thione, which are biologically active and useful molecules such as $\beta$-L-rhamnosyl donors [80e]. Brulikova and Hlavac reported the synthesis, reactivity and biological activity (antiviral, cytotoxicandantibacterial) of5-alkoxymethyluracil analogues (a few molecules are presented in Scheme 48) [80f]. Vembaiyan synthesized C- $\alpha$-D-galactopyranosylamino acid-uridine and $C$ - $[\alpha / \beta]$-L-arabinofuranosyl-amino acid-uridine derivatives, a novel molecular structure type for glycosyltransferase inhibition, and then examined biological measurements (Scheme 48) [80g]. Brodszki et al achieved a five-step synthesis of the lagocyclovir valactate (2', 3'-Dideoxy-3' -fluoro-5-O-[(S)-(+)-2-(I-valyloxy)propionyl] guanosine) hepatitis $\mathrm{B} N$-bucleoside analog from 2-amino-6-chloropurine (Scheme 48) [80h].
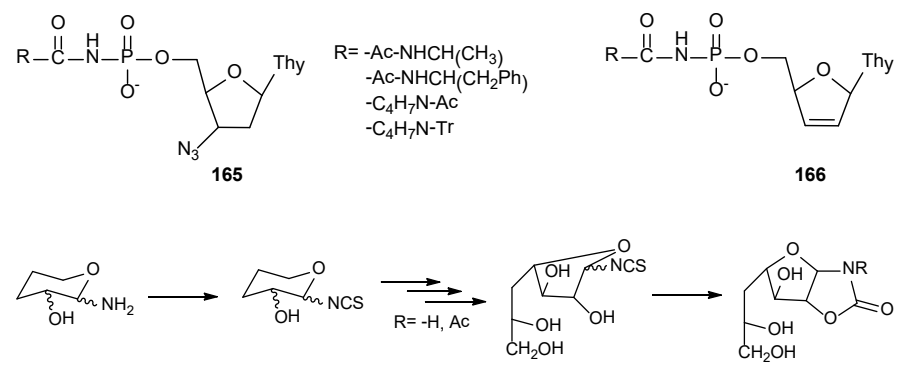

166

167

168

169

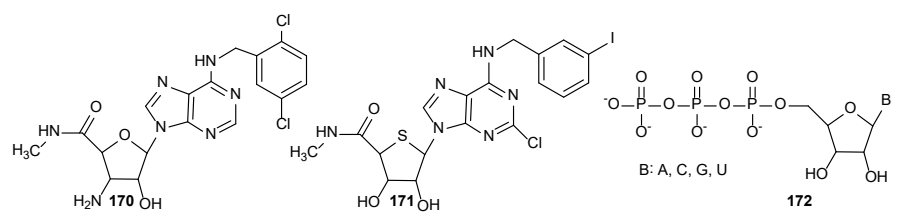

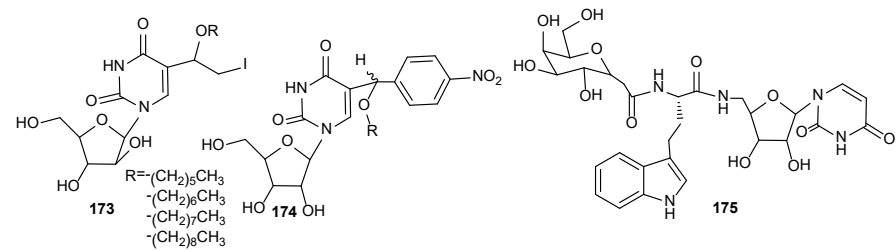

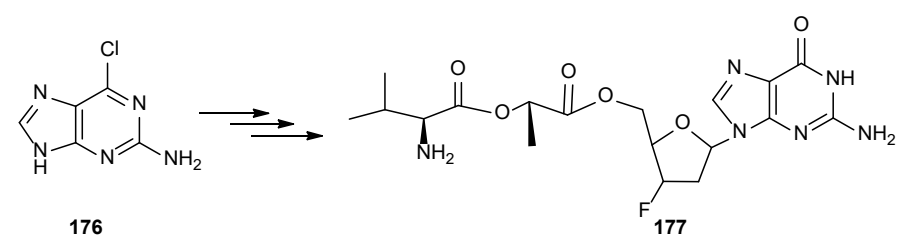

Scheme 48. Ribose and nucleoside derivatives $(165,166,169-174$, 175).

In 2012, Mohamady and Taylor performed the synthesis of nucleoside polyphosphates and their conjugates in excellent yields using sulfonyl imidazolium salts [81a].Voorde studied the inhibton of pyrimidine and purine nucleoside phosphorylases with a 3, 5-dichlorobenzoyl-substituted 2-deoxy-D-ribose-1-phosphate derivative and demonstrated that Cf2891 inhibits the enzymatic degradation of therapeutic nucleoside derivatives [81b]. Lim et al explained the synthesis of L-ribose from L-ribulose with the triplesite mannose-6phosphate isomerase variant from Geobacillus thermodenitrificans [81c]. Avanzo et al reported the design, synthesis and characterization of 1, 2, 4-triazole-Dribosederivatives and studied their antitumor activity against T cell lymphoma cell line (Scheme 49) [81d]. Stevens explained the crystal preparation and characterization of the furanose pentacetate of eight aldohexosols in the D-series, except for L-idose (Scheme 48) [81e]. Vitali et al examined the in vitro antibacterial activity numerous adenosine derivatives (Scheme 48) [81f]. Patil et al developed a strategy on $\alpha$ - and $\beta-C$ arabinosides for the synthesis of the carba-disaccharide analog of Motif C of the cell wall AG complex of Mtb (Scheme 49) [81g]. Almendros explained synthetic nucleo base analogues such as 5-iodo uracil or 2,6-diaminopurine and arabinoside [81h]. Boyle et al synthesized the carbocyclic nucleoside (-)-Abacavir starting from an easily obtainable $\beta$-lactam (Scheme 49) [81].
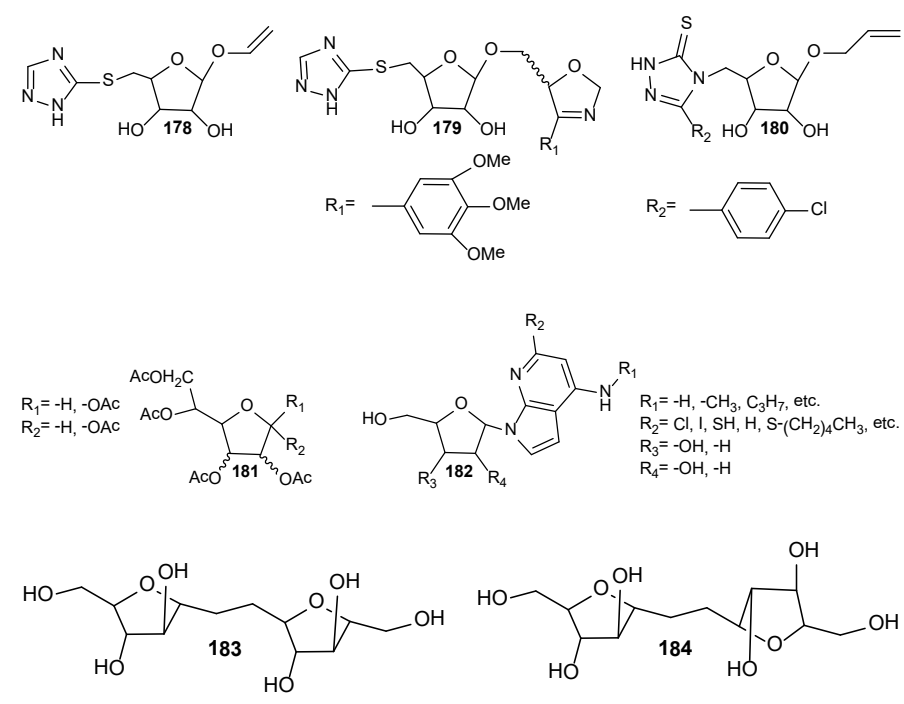<smiles>OCC1O[C@H](CC[C@@H]2OC(CO)[C@H]2O)CC1O</smiles> 


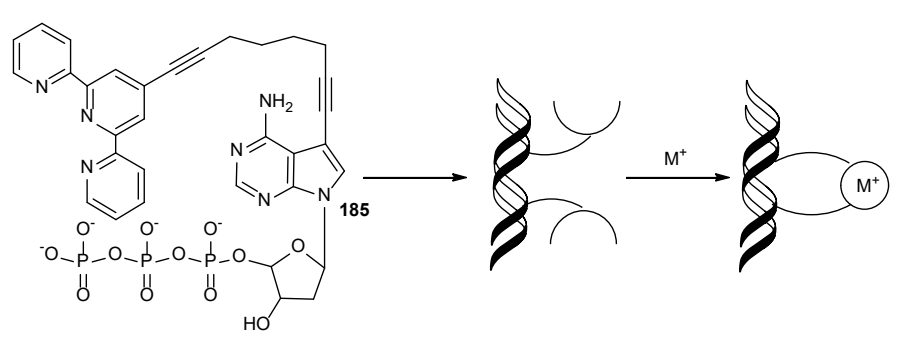

related2'-deoxyfluoroarabino

nucleosides

and

2 'deoxyfluoroarabino nucleosides (Scheme51) [83d]. Lei et al (2014) synthesized 1-((2-hydroxyethoxy) methyl)-5(phenylthio)-1H-1, 2, 4-triazole-3-carboxamide, which is used as anticancer nucleosides from 1, 2, 4-triazole nucleosides (Scheme 51). [83e] Kuchana et al synthesized the xylofuranosyloxymethyl nucleosides using $\mathrm{SnCl}_{4}$ as the activator (Scheme 51) [83f].
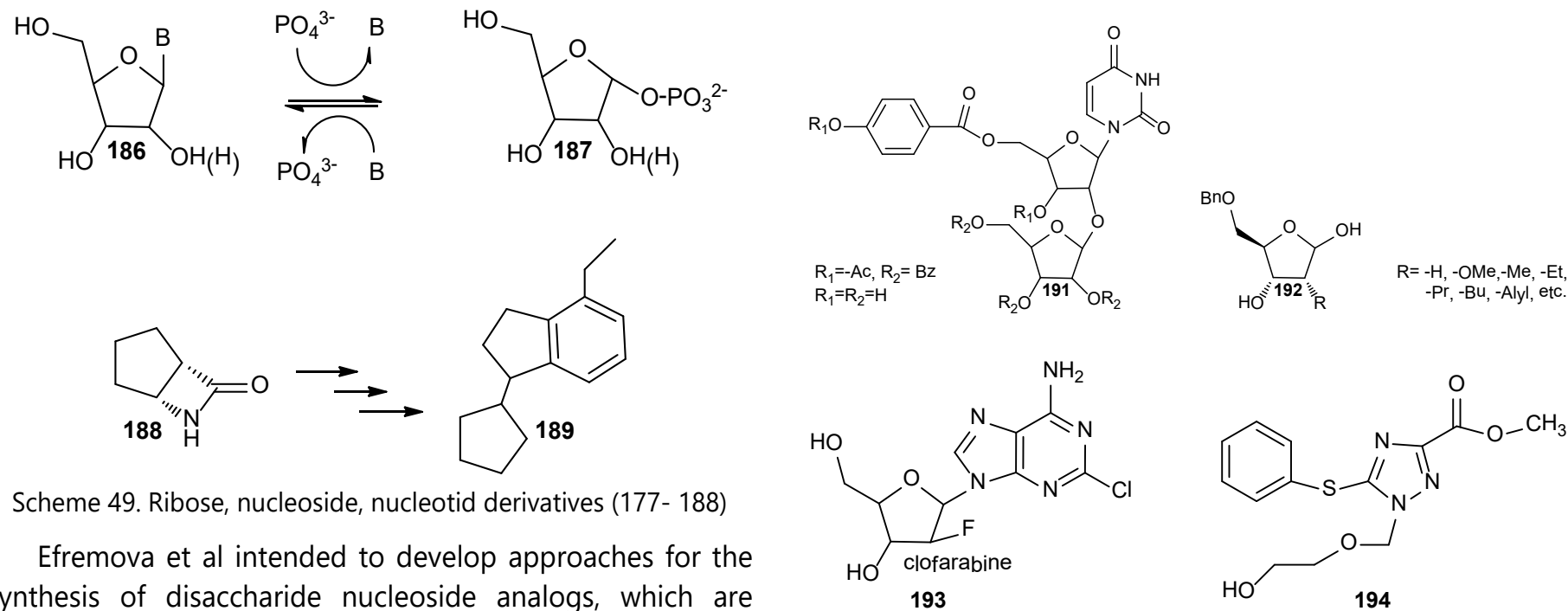

heterocyclic compounds containing primary or secondary amide groups and used as potential inhibitors of human PARP-1, and to examine these analogs as potent inhibitors of human PARP-1 in 2013 (Scheme 50) [82a]. Kalachova et al synthesized modified nucleosides (dARs and dCRs) with 7-iodo-7-deaza-2'-deoxyadenosine and 5-iodo-2'deoxycytidine with the corresponding bipyridine- or terpyridine-octadiynes and their complexation with $\mathrm{Ni}^{2+}$ and $\mathrm{Fe}^{2+}[82 \mathrm{~b}]$.

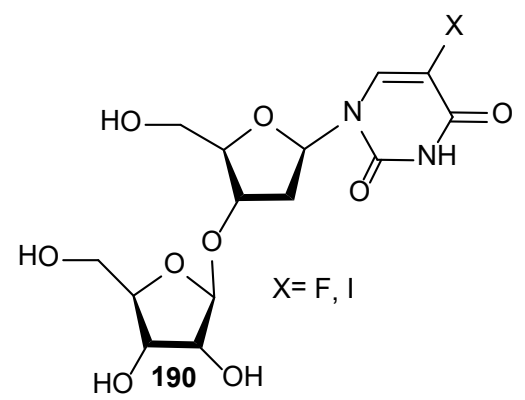

Scheme 50. Disaccharide nucleoside analogues 189

Sylla et al made a new disaccharide nucleoside isolation from Helleborus caucasicus, a plant native to Turkey and Greece, showing the stereo selective synthesis of hellecaucasidae and its $\beta$-anomer and its interesting biological properties, especially anti-cancer activities in 2014 [83a]. Liu et al explained a general method for the synthesis of nucleoside $5^{\prime}-\mathrm{H}$-phosphonothioates containing the coupling of 2', 3'-O-isopropylidene-protected nucleosides with tiethylammonium phosphinate [83b]. Peifer presented a study on the synthesis of pharmaceutically active ribose derivatives, which are widely used clinically (Scheme 51) [83c]. Fateev et al studied the synthesis of 2-chloro-9-(2-deoxy-2fluoro- $\beta$-D-arabinofuranosyl) adenine (clofarabine) and

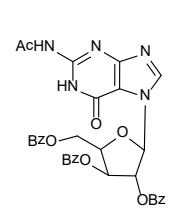

195

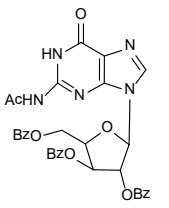

196

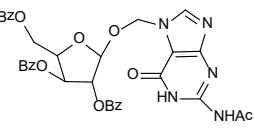

197

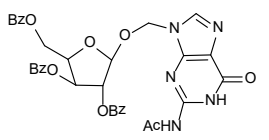

198

Scheme 51. Ribose, nucleoside anoalogues (190-198)

In 2015, Shaughnessy prepared a review on "Palladiumcatalyzed modification of un protected nucleosides, nucleotides, and oligonucleotides" [84a]. Hellecaucaside A, obtained from the roots of Helleborus caucasicus, is a pyrimidine disaccharide nucleoside. Kulikova et al developed synthetic methods to obtain Hellecaucaside A in 2015 (Scheme 52) [84b]. Downey et al reported the one-pot synthesis of nucleosides from unprotected and 5-O-monoprotected D-ribose (Scheme 52) [84c]. BergeronBrlek et al succeeded in a convergent synthesis of the iminoC-nucloside and the iminosugars showing biological activity [84d]. Mahajan et al presented a new study on the development and application of a new AdoR photorefractive process [84e]. He designed a new modular strategy that would facilitate the future production of any 5 -substituted AdoR for Probin synthesis (Scheme 52). Zupancic et al presented the synthesis of nucleosides and condensation reactions with 5-halogen pyrimidines (Scheme 52) [84f]. Oliveira et al reported on a simple and efficient preparation of $2^{\prime}, 3^{\prime}$-Didehydro- $2^{\prime}$, $3^{\prime}$-dideoxy-2'-(2"-(trimethylsilyl)ethylthio) thymidine, the key mediator for the synthesis of anticancer and / or antiviral 2 '-substituted thionucleosides(Scheme52) [84g]. Bessieres et al reviewed the synthesis of carbocyclic nucleosides [84h]. 


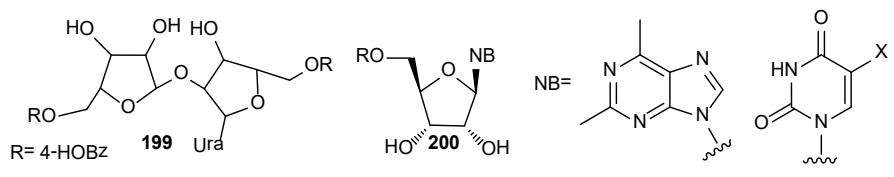<smiles>CN/C=C(/N)NCCCCCCNC(=O)CCCC[C@@H]1SC[C@H]2NC(=O)N[C@@H]21</smiles>

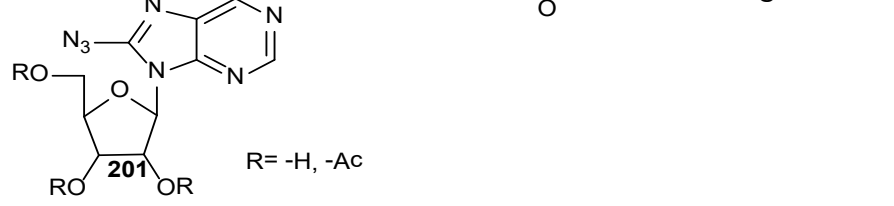

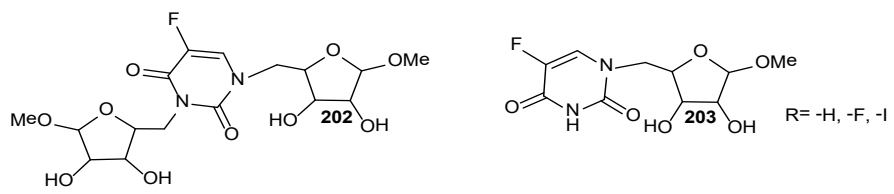<smiles>[R]C1=C(C)C(CO)OC1n1cc(C)c(=O)[nH]c1=O</smiles>

Scheme 52. Ribose, nucleoside derivatives (199-205)

In 2016, Elzagheid wrote a review of the synthesis of $1^{\prime}-$, $2^{\prime}-, 3^{\prime}-, 4^{\prime}$ - and $5^{\prime}$ sugar fluorinated nucleosides [85a]. Mohamady and Taylor synthesized nucleoside triphosphates from 2'-3'-protected nucleosides using trimetaphosphate as the key reagent with good yield (Scheme53) [85b]. Janowsky et al synthesized (N)-methanocarba adenosine derivatives characterized by DAT, NET, and SERT correlated these activities with the structure (Scheme 53) [85c]. Kölmel et al explained the procedure for the preparation of new alkynyl C-nucleosides used to prepare DNA-based polyfluorophores with various fluorophores (Scheme 53) [85d]. Singh et al synthesized 4'-C-ethynyl isomeric dioxolane nucleoside analogs ( $\beta-D, \alpha-D, \beta-L$, and $\alpha-L)$ and evaluated the anti-HIV-1 and anti-HIV-2 activities (Scheme 53 ). The selectivity indices and cytotoxic profiles of the synthesized nucleosides were found to be much better than standard drugs.
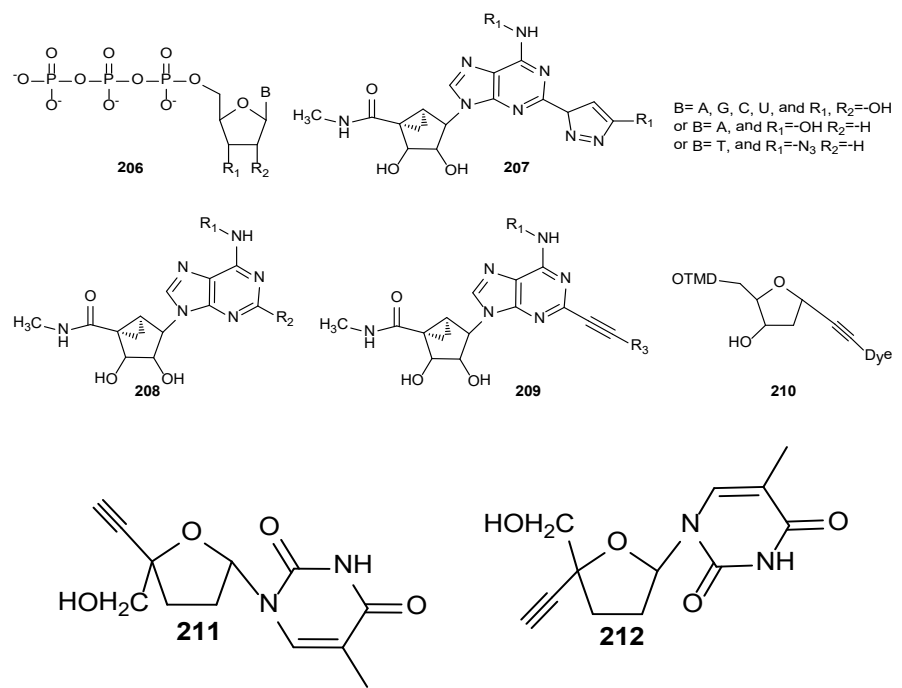

Scheme 53. Ribose, nucleoside, nucleotid anoalogues (206-212).

\section{Conclusion}

Nucleosides used in agriculture (eg herbicides), biotechnology (eg DNA sequencing) and medicine are useful molecules $[1 e, 85]$. Deoxyribonucleic acid is depicted as template for the development of organism. Deoxyribose is a monosaccharide of five carbon atoms with a hydroxyl group in each atom. Cyclopentitols as a ribose derivativeis found as a component of an organism or as a product of microorganism. There are a number of studies for the synthesis of cyclopentitols, because they haved an important role in synthetic organic chemistry in recent years [86]. The priorities of science around the world are new, more efficient and versatile researches showing anti-cancer, antibacterial, antitumor, antimicrobial and anti-hiv properties [1d]. In some natural and synthetic carbocyclic nucleosides, antiviral and antitumor effects such as aristeromycin (1), neplanocin A (2), carbovir (3), abacavir (4) were observed [1]. These important properties make cyclopentitols derivatives important for the synthesis of new drugs. In this paper, we aimed to explain the synthesis of several ribose and nucleoside derivatives that can act as key compounds for the preparation of biological active molecules.

\section{Acknowledgements}

This work was supported by Mersin University (BAP-2015AP4-1235).

\section{References}

1. a. Collins PW, Djuric SW. Synthesis of therapeutically useful prostaglandin and prostacyclin analogs. Chem Rev. 1993; 93: 1533-1564. doi: 10.1021/ cr00020a007

b. Daneker GW, Lund SA, Caughman SW, Staley CA,Wood WC, et al. Antimetastatic prostacyclins inhibit the adhesion of colon carcinoma to endothelial cells by blocking E-selectin expression. Clin Exp Metastasis. 1996; 14(3): 230- 238. doi: 10.1007/BF00053896

c. Siobal MS. Aerosolized prostacyclins. Respir Care. 2004; 49(6): 640-52.

d. Siobal MS. Pulmonary Vasodilators. Respir Care. 2007; 52: 885-889.

e. Kurteva VB, Afonso CAMS. Synthesis of Cyclopentitols by Ring-Closing Approaches. Chem Rev. 2009; 109(12): 6809-6857. doi: 10.1021/ cr900169j

2. a. Ame JC, Spenlehauer C, Murcia G. The PARP super family. Bioessays. 2004; 26: 882-893. doi:10.1002/bies.20085

b. Dantzer F, Rubia GL, Murcia JM, Hostomsky Z,Murcia GD. Base Excision Repair Is Impaired in Mammalian Cells Lacking Poly(ADP-ribose) Polymerase-1. Biochemistry. 2000; 39(25): 7559-7569. doi: 10.1021/ bi0003442

3. Kusaka T, Yamamoto $H$, Shibata M, Muroi M, kishi T, et al. Streptomyces citricolor nov. sp. And a new antibiotic, aristeromycin. J Antibiot (Tokyo). 1968; 21(4): 255-263. doi: 10.7164/antibiotics.21.255

4. Yaginuma $S$, Muto N, Tsujino $M$, Sudate $Y$, Hayashi $M$, et al. Studies on eplanocin a, new antitumor antibiotic. J Antibiot. 1981; 34(6): 359-366. doi: 10.7164/antibiotics.34.359

5. a. Vince R, Hua MJ. Synthesis and anti-HIVactivity of carbocyclic 2', 3'-didehydro-2',3'-dideoxy2,6-disubstituted purine nucleosides. J Med Chem. 1990; 33(1): 17-21. doi: 10.1021/jm00163a004

b. Jones MF, Myers PL, Robertson PC, Storer R, Williamson C. Tota synthesis of (-)-carbovir. J Am Chem Soc. 1991; 1: 2479-2484. doi. 10.1039/P19910002479 
c. Trost BM, Madsen R, Guile SD, Brown B. Palladium-Catalyzed Enantio selective Synthesis of Carbanucleosides. J Am Chem Soc. 2000; 122: 5947-5956. doi: 10.1021/ja9938837

6. a. Daluge SM, Good SS, Faletto MB, Miller WH, St clair MH, et al. 1592U89, A novel carbocyclic nucleoside analog with potent, selective antihuman immune deficiency virus activity. Antimicrob Agent Chemotherapy. 1997; 41(5): 1082-1093.

b. Faletto MB, Miller WH, Garvey E, Clair St MH, Daluge SM, et al. Unique intracellular activation of the potent anti-human immune deficiency virus agent 1592U89. Antimicrob Agents Chemother. 1997; 41(5): 10991107.

c. Foster R, Faulds D. Abacavir. Abacavir Drugs. 1998; 55(5): 729-738. doi: 10.2165/00003495-199855050-00018

d. Mahony WB, Domin BA, Daluge SM, Zimmerman TP. Membrane permeation characteristics of abacavir in human erythrocytes and human T-lymphoblastoid CD4+ CEM cells: comparison with (-)-carbovir. Biochem Pharmacol. 2004; 68: 1797-1805. doi: 10.1016/j. bcp.2004.06.025

7. Marquez VE, Lim Mu-III, Treanor SP, Plowman J, Markovac A, et al. Cyclopentenylcytosine. A carbocyclic nucleoside with antitumor and antiviral properties. J Med Chem. 1988; 31: 1687-1694. doi: 10.1021/ jm00117a004

8. Matsuda A, Sasaki T. Antitumor activity of sugar-modified cytosine nucleosides. Cancer Science. 2004; 95(2): 105-111. doi: 10.1111/j.1349-7006.2004.tb03189.x

9. Mitsuya $\mathrm{H}$, Weinhold KJ, Furman PA, Clair MH St, Lehrman SN, et al. 3'-azido-3'-Deoxythymidine (bw a509u): an antiviral agent that inhibits the infectivity and cytopathic effect of human t-lymphotropic virus type iii/lymphadenopathy-associated virus in vitro. Proc Natl Acad Sci. 1985; 82(20): 7096-7100.

10. Chou TS, Heath PC, Patterson LE, Poteet LM, Lakin RM, et al. Stereospecific Synthesis of 2-Deoxy-2,2-difluororibonolactone and Its Use in the Preparation of 2'-Deoxy-2',2'-difluoro- $\beta$-D-ribofuranosyl Pyrimidine Nucleosides: The Key Role of Selective Crystallization. Synthesis. 1992; 6: 565-570. doi: 10.1055/s-1992-26167

11. Fischer E, Helferich B. Synthetische Glucoside der Purine. Eur J Inor Chem. 1914; 47(1): 210- 235. doi: 10.1002/cber.19140470133

12. a. Johnson TB, Hilbert GE. The Synthesis of Pyrimidine-Nucleosides. Science. 1929; 69(1796): 579-580. doi: 10.1126/science.69.1796.579

b. Hilbert GE, Johnson TB. Researches on pyrimidines. Cxvii. A method for the synthesis of nucleosides. J Am Chem Soc. 1930; 52(11): 4489-4494. doi: 10.1021/ja01374a045

13. Levene PA, Compton J. Synthetic nucleosides: V.Theophylline-D Allomethyloside. J Biol Chem. 1937; 117: 37-43.

14. a. Howard GA, Kenner GW, Lythgoe B, Todd AR. Experiments on the synthesis of purine nucleosides. Part XIV. An interpretation of some interconversion reactions of N-glycosides. J Chem Soc. 1946; 855-861. doi: $10.1039 / J R 9460000855$

b. Howard GA, Lythgoe B, Todd AR. A synthesis of cytidine. J Chem Soc. 1947; 1052-1054. doi: 10.1039/JR9470001052.

15. a. Barker GR. The chemistry of ribose and its derivatives. Part I. Methyl-Dribofuranoside and the characterisation of trimethyl D-ribofuranose. J Chem Soc. 1948; 2035-37. doi: 10.1039/JR9480002035

b. Baker HG. The ecotypes of melandrium dioicum (I. Emend.) Coss. \& germ. New Phytologist. 1948; 47(1): 131-145. doi: 10.1111/j.1469-8137.1948. tb05096.x

16. Friedkin $M$, Kalckar HM. The Phosphorolysis and resynthesis of purine Desoxyribose Nucleioside. J Biol Chem. 1950; 184: 437-448.

17. Racker EJ. Enzymatic Synthesis and Breakdown Of Desoxyribose Phosphate. Biol Chem 1952; 196: 347-365.

18. Kalckar HM. The role of phosphoglycosyl compounds in the biosynthesis of nucleosides and nucleotides. Biochim Biophys Acta. 1953; 12(1-2): 250264. doi: 10.1016/0006-3002(53)90144-9
19. a. Baker BR, Schaub Re. Achromycin.1 synthetic studies. lii. Synthesis of 3-amino-d-ribose, a hydrolytic product. J Am Chem Soc. 1953; 75(15): 3864-3865. doi: 10.1021/ja01111a529

b. Baker BR, Joseph JP, Williams JH. Puromycin. Synthetic studies. Vii. Partial synthesis of amino acid analogs. J Am Chem Soc. 1954; 76(10): 2838-2838. doi: 10.1021/ja01639a072

c. Baker BR, Schaub RE, Joseph PJ, Williams JH. Total Synthesis of the Antibiotic Puromycin. J Am Chem Soc. 1954; 76: 4044-4045. doi: 10.1021/ja01644a064

20. Ness RK, Diehl HW, Fletcher Jr. HG. New Benzoyl Derivatives of D-Ribofuranose and aldehydo-D-Ribose. The Preparation of Crystalline 2,3,5-Tri-O-benzoyl- $\beta$-D-ribose from D-Ribose. J Am Chem Soc. 1954; 76(3): 763-767. doi: 10.1021/ja01632a038

21. a. Friedkin M, Roberts DJ. The Enzymatic Synthesis of Nucleosides ii. Thymidine and Related Pyrimidine nucleosides. Biol Chem. 1954; 207(1): 257-266.

b. Friedkin M. The enzymatic synthesis of nucleosides. I. Thymidine phosphorylase in mammalian tissue. J Biol Chem. 1954; 207(1): 245256.

22. Mowery Jr, Dwight F. Chromatographic Adsorption. IV. Cation Exchange Resins as Catalysts in Glycoside Formation. J Am Chem Soc. 1955; 77(6): 1667-1669. doi: 10.1021/ja01611a075

23. Cardwell HME, Kilner AEH. Elimination reactions. Part I. Acid-catalysed enolisation and substitution reactions of ketones. J Chem Soc. 1951; 24302441. doi: $10.1039 / J R 9510002430$

24. Barker GR, NooneTM, Smith DCC, SpoorsW. The chemistry of ribose and its derivatives. Part $\mathrm{V}$. The synthesis of methyl ethers by partial methylation. J Chem Soc. 1955; 1327-1332. doi: 10.1039/JR9550001327

25. Kissman HM, Pidacks C, Baker BR. Puromycin Synthetic Studies XI. D-Ribofuranosyl Derivatives of 6-Dimethylaminopurine. J Am Chem Soc. 1995; 77(1): 18-24. doi: 10.1021/ja01606a005

26. a. Baker BR, Schaub RE, Joseph JP, Williams JH. Puromycin. Synthetic Studies. VII. Partial Synthesis of Amino Acid Analogs. J Am Chem Soc. 1955; 77: 1-7. doi: 10.1021/ja01606a001

b. Baker BR, Schaub RE, Williams JH. Puromycin. Synthetic Studies. VIII. Synthesis of 3-Amino-3-deoxy-D-ribofuranoside Derivatives. A Second Synthesis of 3-Amino-3-deoxy-Dribose. J Am Chem Soc. 1955; 77(1): 7-12. doi: 10.1021/ja01606a002

c. Baker BR, Schaub RE, Joseph JP, Williams JH. Puromycin. Synthetic Studies. IX. Total Synthesis. J Am Chem Soc. 1955; 77(1): 12-15. doi: 10.1021/ja01606a003

d. Baker BR, Joseph JP. Puromycin Synthetic Studies. X. A Novel Breakdown of the Purine Ring System. J Am Chem Soc. 1955; 77(1): 15-18. doi: 10.1021/ja01606a004

e. Baker BR, Schaub RE. Puromycin. Synthetic Studies. XII.1 Synthesis of the $\alpha$-Anomer of 6-Dimethylamino-9-(3'-amino-3'-deoxy-Dribofuranosyl)-purine. J Am Chem Soc. 1955; 77(9): 2396-2399. doi: 10.1021/ja01614a011

f. Baker BR, Schaub RE. Puromycin. Synthetic Studies. XIV. Use of the $\mathrm{N}$-Phthalyl Blocking Group for Synthesis of Aminonucleosides. Re. J Am Chem Soc. 1955; 77: 5900-5905. doi: 10.1021/ja01627a0378

g. Baker BR, Joseph JP, Schaub RE. Puromycin. Synthetic Studies. XIV. Use of the N-Phthalyl Blocking Group for Synthesis of Aminonucleosides. J Am Chem Soc. 1955; 77: 5905-5910. doi: 10.1021/ja01627a038

h. Baker BR, Schaub RE, Kissman HM. Puromycin. Synthetic Studies. XV. 3'-Amino-3'-deoxyadenosine. J Am Chem Soc. 1955; 77: 5911-5915. doi: 10.1021/ja01627a039

27. Kissman HM, Baker BR. The Synthesis of Certain 5-Deoxy-Dribofuranosylpurines. J Am Chem Soc. 1957; 79(20): 5534-5540. doi: 10.1021/ja01577a055.

28. Shaw G, Warrener RN, Maguire MH, Ralph RK. Purines, pyrimidines, and glyoxalines. Part IX. Syntheses of uridine, 2-thiouridine, and some related compounds. J Chem Soc. 1958; 2294-299. doi: 10.1039/JR9580002294 
29. Mac Donald DL, Fletcher HG. 2-Deoxy-D-ribose. II. The Synthesis of 2-Deoxy-D-ribose 5-Phosphate. J Am Chem Soc. 1959; 81(14): 3719-3722. doi: 10.1021/ja01523a057.

30. a. Ness RK, Mac Donald DL, Fletcher Jr.HG. 2-Deoxy-D-ribose. VII.1 Crystalline 2-Deoxy-3, 5-di-O-p-nitrobenzoyl-D-ribosyl Chloride and Related Derivatives. J Org Chem 1961; 26(8): 2895-2899. doi: 10.1021/ j001066a065

b. Potgieter DJJ, Mac Donald DL .The Synthesis of Certain Benzylidene Derivatives of D-Ribose and Ribitol. J Org Chem. 1961; 26(10): 39343938. doi: 10.1021/jo01068a072

c. Fox JJ, Yung NC, Wempen I, Hoffer M. Nucleosides. XII. Direct Synthesis of 2'-Deoxycytidine and its $\alpha$-Anomer1,2. J Am Chem Soc. 1961; 83(19): 4066-4070. doi: 10.1021/ja01480a027

31. a. Mac Donald DL, Fletcher HG. 2-Deoxy-D-ribose. VIII.1 Synthesis of the Anomeric 2-Deoxy-D-ribofuranose 1-Phosphates2. J Org Chem 1962; 84: 1262-1265. doi: 10.1021/ja00866a041

b. Serfontein WJ, Jordaan JH. Potential Inhibitors of Cancerous Growth. I. Synthesis of Cyclic Nitrogen Mustard Phosphamide Ester Derivatives of D-Ribose. J Org Chem. 1962; 27(9): 3332-3334. doi: 10.1021/ jo01056a519

32. a. Reist EJ, Gueffroy DE, Goodman L. Synthesis of 4-Thio-D- and -L-ribofuranose and the Corresponding Adenine Nucleosides. J Am Chem Soc. 1964; 86(24): 5658-5663. doi: 10.1021/ja01078a050

b. Moffatt JG. A General Synthesis of Nucleosides-5' Triphosphates. Can J Chem. 1964; 2(3): 599-604. doi: 10.1139/v64-087

c. 1. Baker BR, Neilson T.J. Synthetic Nucleosides. LIX.1, 2 Studies on the Synthesis of cis-2,3-Diamino Sugars.II. the Thiourea Neighboring Group. J Org Chem. 1964; 29(5): 1051-1056. doi: 10.1021/j001028a016

2. Baker BR, Neilson T. Synthetic Nucleosides. LX.1, 2 Studies on the Synthesis of cis-2,3-Diamino Sugars. III. The Urea Neighboring Group. J Org Chem. 1964; 29(5): 1057-1062. doi: 10.1021/ jo01028a017

3. Baker BR, Neilson T. Synthetic Nucleosides. LXI.1,2 Studies on the Synthesis of cis-2,3.Diamino Sugars. IV.The Guanidine Neighboring Group. J Org Chem. 1964; 29(5): 1063-1067. doi: 10.1021/jo01028a018

d. Underwood GE, Wisner CA, Weed SD. Cytosine Arabinoside (CA) and Other Nucleosidesin HerpVirus Infections. Arch Ophthalmol. 1964; 72(4): 505-512. doi: 10.1001/archopht.1964.00970020505014

33. a. Leonard NJ, Laursen RA. Synthesisof3- $\beta$-D-Ribofuranosyladenineand(3$\beta$-D-Ribofuranosyladenine)-5'-phosphate*. Biochemistry. 1965; 4(2): 354-365. doi: 10.1021/bi0087a027

b. Leonard NJ, Laursen RA. Synthesis and Properties of Analogs of Adenosine Diphosphate, Adenosine Triphosphate, and Nicotinamide-Adenine Dinucleotide Derived from3- $\beta$-Ribofuranosyladenine (3-Isoadenosine)*. Biochemistry. 1965; 4(2): 365-376. doi: 10.1021/bi00878a028

c. Murray DH, Prokop J. Synthesis of 3 '-deoxynucleosides II. Synthesis of 9-(3-deoxyaldofuranosyl) adenines derived from 3-deoxy-D-glucose. J Pharma Sci. 1965; 54(10): 1468-1473. doi: 10.1002/jps.2600541014

34. a. Ferrier RJ, Prasad D. Boric acid derivatives as reagents in carbohydrate chemistry. Part V. The interaction of phenylboronic acid with methyl pentopyranosides: syntheses of 3- and 2,4-substituted ribose derivatives. J Chem Soc. 1965; 7425-7428. doi: 10.1039/JR9650007425

b. 1. Baker BR, Hullar TL. Synthetic Nucleosides. LXV.1a Studies on the Synthesis of cis-2,3-Diamino Sugars.V.1bNeighboring Group Reactions with Derivatives of Methyl2-Amino-4,6-O-benzylidene2-deoxy- $\alpha$-D-altropyranoside1c. J Org Chem. 1965; 30(12): 40384044. doi: $10.1021 / \mathrm{jo} 01023 \mathrm{a} 012$

2. Baker BR, Hullar TL. Synthetic Nucleosides. LXVI. Studies on the Synthesis of cis-2,3-Diamino Sugars.VI. Neighboring Group Reactions with Methyl 4,6-O-Benzylidene-3-deoxy-2-Omethanesulfonyl-3-thioureido - $\alpha$-D-glucopyranoside1a,.b. J Org Chem. 1965; 30(12): 4045-4048. doi: 10.1021/jo01023a013
3. Baker BR, Hullar TL. Synthetic Nucleosides. LXVII. Studies on the Synthesis of cis-2,3-Diamino Sugars. VII. Synthesis and Reactions of Some N-p-Tolylsulfonyl Derivatives of 2-Amino-2-deoxy-Daltrose, 3-Amino-3-deoxy-D-glucose, and 2, 3-Dideoxy-2,3imino-D-mannose1a,b. J Org Chem. 1965; 30(12): 4049-4053. doi: 10.1021/jo01023a014

c. 1. Baker BR, Hullar TL. Synthetic Nucleosides. LXVIII. Studies on the Synthesis of cis-2,3-Diamino Sugars. VIII. Derivatives of 2,3-Diamino-2,3-dideoxy-D-ribose and 2,3-Dideoxy-2,3-iminoD-ribose1a,b. J Org Chem. 1965; 30(12): 4053-4056. doi: 10.1021/ j001023a015

2. Baker BR, Buss DH. Synthetic Nucleosides. LXIII.1,2 Synthesis and Reactions of Some $\alpha$-Sulfonyloxy Oxo Sugars. J Org Chem. 1965; 30(7): 2304-2308. doi: 10.1021/j001018a044

3. Baker BR, Buss DH. Synthetic Nucleosides. LXIV.1,2 Synthesis and Stereospecific Reduction of Some 2(3)-Acylamino-3(2)oxopyranosides. J Org Chem. 1965; 30(7): 2308-2311. doi: 10.1021/jo01018a045

35. a. Fox JJ, Miller N, Wempen I. Nucleosides. XXIX. 1- $\beta$-D-Arabinofuranosyl5-fluorocytosine and Related Arabino Nucleosides1. J Med Chem. 1966; 9(1): 101-105. doi: 10.1021/jm00319a025

b. Leonard NJ, Carraway KL. 5-Amino-5-deoxyribose derivatives.Synthesis and use in the preparation of Reversed Nucleosides. J Heterocyclic Chem. 1966; 3(4): 485-489. doi: 10.1002/jhet.5570030420

c. Reist EJ, Fisher L, Gueffroy DE. Neighboring-Group Participation.The Preparation of Derivatives of D-Ribose and L-Lyxose from L-Arabinose1. J Org Chem. 1966; 31(1): 226-229. doi: 10.1021/jo01339a050

d. Baker BR, Buss DH. Synthetic Nucleosides. LXIX.1,2 Synthesis of Some New Types of Branched-Chain Amino Sugars. J Org Chem. 1966; 31(1): 217-220. doi: 10.1021/jo01339a047

e. Lerner ML, Kohn P. The Preparation of 9-D-Mannofuranosyladenine1. J Org Chem. 1966; 31(1): 339-341. doi: 10.1021/jo01339a514

36. a. Ali SS, Mepham TJ, IME Thiel, Buncel E, Jones JKN. Reactions of sugar chlorosulfates : Part VIII. D-ribose and its derivatives. Carbohydr. Res. 1967; 5(2): 118-125. doi: 10.1016/S0008-6215(00)86033-4

b. Onodera K, Hirano S, Masuda F. Nucleosides and related substances : Part VI. The synthesis of $9-\alpha$ - $d$-ribofuranosyladenine ( $\alpha$-adenosine). Carbohydr. Res. 1967; 4(3):263-266. doi: 10.1016/S0008-6215(00)850120

c. Eckstein F, Gindl H. Synthesis of nucleoside 5'-polyphosphorothioates. Biochim. Biophys. Acta Nucleic Acids Protein Synth. 1967; 149(1): 35-40. doi: 10.1016/0005-2787(67)90688-0

37. a. Fukami $H$, Koh HS, Sakata T, Nakajima M. The synthesis of 5-deoxy- $( \pm)-$ allose derivatives and 4-deoxy-( \pm )-ribose from myo-inositol. Tetrahedron Lett. 1968; 9(14): 1701-1704. doi: 10.1016/S00404039(01)99032-X

b. Lerner ML, Kohn BD, Koh P. Preparation of nucleosides via isopropylidene sugar derivatives. III. Synthesis of 9-.beta.-Dgulofuranosyladenine and 9-.alpha.L-lyxofuran-osyladenine. J. Org. Chem. 1968; 33(5): 1780-1783. doi: 10.1021/jo01269a017

c. Sowa W. Convenient synthesis of 3-amino-3-deoxy-D-ribose. Can. J. Chem. 1968; 46(9): 1586-1589. doi: 10.1139/v68-263

38. a. Lance DG, Szarek WA, Jones JKN. Some O-isopropylidene derivatives of D-ribose diethyl dithioacetal. Can. J. Chem. 1969; 47(15): 2889-2891. doi: 10.1139/v69-479

b. Lerner M.L. Preparation of nucleosides via isopropylidene sugar derivatives. IV. Synthesis of 9-[.alpha.(and .beta.)-L-erythro furanosyl] adenine. J. Org .Chem. 1969; 34(1): 101-103. doi: 10.1021/jo00838a024

39. a. Follmann $H$, Hogenkamp HPC. Synthesis of ribose and of adenine nucleotides containing oxygen-18. J. Am.Chem. Soc. 1970; 92(3): 671677. doi: 10.1021/ja00706a040

b. Niedballa $U$, Vorbrüggen $H$. A General Synthesis of Pyrimidine Nucleosides*. Angew. Chem. 1970; 9(6): 461-462. doi: 10.1002/ anie. 197004612 
40. Ryan KJ, Acton EM, Goodman L. Synthesis of 2-thio-D-ribose and 2'-thioadenosine derivatives. J. Org. Chem. 1971; 36(18): 2646-2657. doi: 10.1021/j000817a018

41. a. 1. Lerner ML. Interconversions of hexofuranosyl nucleosides.I. Synthesisof9-.beta.-L gulofuranosyladenine from 9-alpha.-Dmannofuranosyladenine. J. Org. Chem. 1972; 37(3): 470-473. doi: 10.1021/jo00968a031

2. Lerner ML. Interconversion of hexofuranosyl nucleosides. III. Synthesis of a 4', 5'-unsaturated hexofuranosyl nucleoside. J. Org. Chem. 1972; 37(3): 477-481. doi: 10.1021/jo00968a033

3. Lerner ML. Interconversions of hexofuranosyl nucleosides. IV. Synthesis of nucleosides derived from 6-deoxy-L-glucose. J. Org. Chem. 1972; 37(26): 4386-4391. doi: 10.1021/jo00799a030

b. Witkowski JT, Robins RK, Sidwell RW, Simon LN. Design, synthesis, and broad spectrum antiviral activity of 1-.beta.-D-ribofuranosyl-1,2,4triazole-3-carboxamide and related nucleosides. J. Med.Chem. 1972; 15(11): 1150-1154. doi: 10.1021/jm00281a014

42. a. Evely L, Hall LD, Lynn L, Steiner PR, Stokes DH . Some 3-C-(dimethoxy) phosphinyl derivatives of D-glucose, D-allose, and D-ribose. Carbohydr. Res. 1973; 7(1): 21-27. doi: 10.1016/S0008-6215(00)82420-9

b. Rabelo JJ, Van ES. Derivatives of 5-seleno-D-ribose. Carbohydr.Res. 1973; 30(2): 381-385. doi: 10.1016/S0008-6215(00)81826-1

c. Lerner ML. Interconversions of hexofuranosyl nucleosides. V. Synthesis and re examination of the structure of 9-(6-deoxy-.alpha.-L-mannofuranosyl) adenine. J. Org. Chem. 1973; 38(21): 3704-3709. doi: 10.1021/jo00961a010

43. a. Niedballa $U$, Vorbrüggen $H$. Synthesis of nucleosides. 9. General synthesis of N-glycosides. I. Synthesis of pyrimidine nucleosides. J. Org. Chem. 1974; 39(25): 3654-3660. doi: 10.1021/jo00939a008

b. Hampton A, Perini F, Harper PJ. Derivatives of phosphonate and vinyl phosphate analogs of ribose 5-phosphate. Carbohydr. Res. 1974; 37(2): 359-367. doi: 10.1016/S0008-6215(00)82926-2

c. Rabelo J, Van EsT. Selenoxides of D-xylose and D-ribose derivatives. Carbohydrate Res. 1974; 32(1): 175-179. doi: 10.1016/S00086215(00)82477-5

44. a. Lerner ML. Preparation of 9-alpha.-D-idofuranosyladenine. J. Org. Chem. 1975; 40(16): 2400-2402. doi: 10.1021/jo00904a030

b. Schwartz AL. Lerner ML. Synthesis and properties of N-(2, 3, 5-tri-Oacetyl Dribofuranosyl) maleimide. J. Org. Chem. 1975; 40(1): 24-28. doi: 10.1021/j000889a005

45. a. Van EsT. The synthesis of O-methyl derivatives of 4-thiopentofuranosides and 2,5 anhydropentoses. Carbohydr. Res. 1976; 46(2): 237-244. doi: 10.1016/S0008-6215(00)84295-0

b. Lerner ML. Adenine nucleosides derived from 6-deoxyhexofuranoses. J. Org. Chem. 1976; 41(2): 306-310. doi: 10.1021/jo00864a026

c. Niedballa $U$, Vorbrüggen $\mathrm{H}$. Synthesis of nucleosides 17. A general synthesis of $\mathrm{N}$-glycosides. 6 . On the mechanism of the stannic chloride catalyzed silyl Hilbert-Johnson reaction. J. Org. Chem. 1976; 41(12): 2084-2086. doi: 10.1021/jo00874a002

46. a. Blumberg K, Fuccello A, Es TV. Selenium derivatives of L-arabinose, D-ribose, and D-xylose. Carbohydr. Res. 1977; 59(2): 351-362. doi: 10.1016/S0008-6215(00)83177-8

b. EsT V. Formation of 2,5-anhydropentose dibenzyl dithioacetals from pentose dibenzyl di thioacetals in acid solution. Carbohydr. Res. 1977; 58(2): 488-493. doi: 10.1016/50008- 6215(00)84377-3

47. a. Schaeffer HJ, Beauchamp L, Miranda PD, Elion GB, Bauer DJ, Collins P. 9-(2-Hydroxyethoxymethyl) guanine activity against viruses of the herpes group. Nature. 1978; 272: 583-585. doi: 10.1038/272583a0

b. 1. Lerner ML. Preparation of 9-(5-deoxy-.alpha.-D-arabinofuranosyl) adenine from D-ribose. J. Org.Chem. 1978; 43(1): 161-163. doi: 10.1021/jo00395a038

2. Lerner ML. 9-(6-Deoxyhexofuranosyl) adenine nucleosides. Further studies on the acetolysis of hexofuranosides. J. Org. Chem. 1978; 43(5): 962-965. doi: 10.1021/j000399a035
3. Lerner ML. Preparation of the enantiomeric forms of 9-(5, 6-dideoxy-.beta.-D-ribo-hex-5-enofuranosyl) adenine. J. Org. Chem. 1978; 43(12): 2469-2473. doi: 10.1021/jo00406a038

c. Ueda T, Miura K, Kasai T. Synthesis of 6-Thioguanine and 2, 6-Diaminopurine Nucleosides and Nucleotides from Adenine Counterparts via a Facile Rearrangement in the Base Portion (Nucleosides and Nucleotides.XIX). Chem Pharm Bull. 1978; 26(7): 2122-2127. doi: 10.1248/cpb.26.2122

48. a. Lerner ML. Preparation of the $E$ and $Z$ isomers of 9-(5, 6-dideoxy-.beta.D-erythro-hex-4-enofuranosyl) adenine. J. Org. Chem. 1979; 44(24): 4359-4364. doi: 10.1021/jo01338a024

b. Ferris $P$, Singh $S$, Newton TA. Synthesis of quinazoline nucleosides from ribose and anthranilonitrile. Application of phase-transfer catalysis in nucleoside synthesis. J. Org. Chem. 1979; 44(2): 173-178. doi: 10.1021/ jo01316a003

c. Keyser GE, Bryant JD, Barrio JR. lodomethylethers from 1,3-dioxolane and 1,3-oxathiolane: preparation of acyclic nucleoside analogs. Tetrahedron Lett. 1979; 20(35): 3263-3264. doi: 10.1016/S0040-4039(01)95379-1

49. a. Sun $K M$, Fraser-Reid B. A synthesis of $(+)$ and (-) methyl nonactate from a derivative of D-ribose. J. Chem. 1980; 58(23): 2732-2735. doi: 10.1139/ v80-437

b. Barrio JR, Bryant JD, Keyser GE. A direct method for the preparation of 2hydroxyethoxymethyl derivatives of guanine, adenine, and cytosine. J. Med. Chem. 1980; 23(5): 572-574. doi: 10.1021/jm00179a020

50. a. Khadem HSE, Nelson V. Synthesis of crystalline derivatives of 6-deoxyd-allo- and -I-talo-furanosyl bromide suitable for nucleoside synthesis. Carbohydr. Res. 1981; 98(2): 195-201. doi: 10.1016/S00086215(00)80814-9

b. Daskalov HP, Sekine M, Hata T. Synthesis and properties of O6substituted guanosine derivatives. Chem. Soc. Jpn. 1981; 54: 3076-3083. doi: 10.1246/bcsj.54.3076

c. Vorbrüggen H, Krolikiewicz K, Bennua B. Nucleoside syntheses, XXII1) Nucleoside synthesis with trimethylsilyl triflate and perchlorate as catalysts. Eur. J. Inorg. Chem. 1981; 114(4): 1234-1255. doi: 10.1002/ cber.19811140404

51. a. Mukaiyama T,Miwa T, NakatsukaT. A Stereoselective Synthesis of 2-Amino-2-Deoxy-D-ArabinoseAnd-D-Ribose. Chem. Lett. 1982; 11: 145-148. doi: 10.1246/cl.1982.145

b. Pasque MK, Spray TL, Pellom GL, Van Trigt P, Peyton RB, et al. Riboseenhanced myocardial recovery following ischemia in the isolated working rat heart. J. Thorac Cardiovasc. Surg. 1982; 83(3): 390-398.

c. Sims JL, Sikorski GW, Catino DM, Berger SJ, Berger NA, et al. Poly(adenosinediphosphoribose. polymerase inhibitors stimulate unscheduled DNA synthesis in normal human lymphocytes. Biochemistry. 1982; 21(8): 1813-1821. doi: 10.1021/bi00537a017

52. a. Hiratsuka T. New ribose-modified fluorescent analogs of adenine and guanine nucleotides available as subtrates for various enzymes. Biochim. Biophys. Acta. 1983; 742(3): 496-508. doi: 10.1016/01674838(83)90267-4

b. Robins MJ, Parker JMR. Chiral transformations of D-ribose to 2-( $\beta$-Dribofuranosyl)-L and D-glycine and an anhydroallose hemiacetal used in C-nucleoside synthesis. Can J. Chem. 1983; 61(2): 312-316. doi: 10.1139/v83-056

53. a. Forrest AK, Schmidt RR. De novo-synthesis of carbohydrates preparation of 4-amino-4-deoxy-?,?-ribose derivatives. Tetrahedron Lett. 1984; 25(17): 1769-1772. doi: 10.1016/S00404039(01)90037-1

b. Sato T, Hayakawa Y, Noyori RA. A stereo controlled total synthesis of C-nucleosides. Bull. Chem. Soc. Jpn. 1984; 57(9): 2515-2525. doi: 10.1246/bcsj. 57.251

54. a. Aslani-Shotorbani G, Buchanan JG, Edgar AR, Shahidi PK. The isopropylidenation of $d$-ribose diethyldithioacetal and ribitol. A new synthesis of $\alpha$-and $\beta$-ibofuranosylethyne via 2,3:4,5-di-Oisopropylidene-aldehydo-d-ribose. Carbohydr. Res. 1985; 136: 37-52. doi: 10.1016/0008-6215(85)85184-3 
b. YamamatoY, Kirihata M, Ichimoto I, Ueda H. Stereo selective Synthesis of 2-Amino-2-deoxy-d-arabinose and 2-Deoxy-d-ribose. Agric. Biol. Chem. 1985; 49(5): 1435-1439. doi: 10.1080/00021369.1985.10866889

c. Berger NA, Berger SJ, Catino DM, Petzold SJ, Robins RK. Modulation of nicotinamide adenine dinucleotide and poly(adenosine diphosphoribose) metabolism by the synthetic " $\mathrm{C}$ " nucleoside analogs, tiazofurin and selenazofurin. A new strategy for cancer chemotherapy. J. Clin. Invest. 1985; 75(2): 702-709. doi: 10.1172/JCl111750

55. a. Hughes NA, Wood CJ. 5-Thiopyranoses. Part 8. Sulphur participation in displacement reactions of sulphonate esters of 5-thio-D-ribose and 5-thio-D-xylose derivatives. J. hem. Soc. Perkin Trans. 1986; 1: 695-700. doi: 10.1039/P19860000695

b. Schmidt RR. Hetero-Diels-Alder reaction in highly functionalized natural product synthesis. Acc. Chem. Res. 1986; 19(8): 250-259. doi: 10.1021/ar00128a004

56. a. Mc Elwain AC, Pollack JD. Synthesis of Deoxyribomononucleotides in Mollicutes: Dependence on Deoxyribose-1-Phosphate and PPi. J. Bacteriol. 1987; 169(8): 3647-3653. doi: 00219193/87/083647$07 \$ 02.00 / 0$

b. Beigelman LN, Ermolinsky BS, Gurskaya GV, Tsapkina EN, Karpeisky MY, et al. New syntheses of 2'-C-methyl nucleosides starting from d-glucose and d-ribose. Carbohydr. Res. 1987; 166(2): 219-232. doi: 10.1016/00086215(87)80059-9

57. a. Mc Elwain MC, Williams MV, Pollack JD. Acholeplasma laidlawii B-PG9 Adenine-Specific Purine Nucleoside Phosphorylase That Accepts Ribose-1-Phosphate, Deoxyribose-1-Phosphate, and Xylose-1Phosphate. J. Bacteriol. 1988; 170(2): 564-567. doi: 00219193/88/020564-04\$02.00/0

b. Shapiro R. Prebiotic ribose synthesis: A critical analysis. Orig of Life Evol Biosph. 1988; 18(1-2): 71-85. doi: 10.1007/BF02422027

c. Hennen WJ, Sweers HM, Wang YF, Wong CH. Enzymes in carbohydrate synthesis. Lipase-catalyzed selective acylation and deacylation of furanose and pyranose derivsative. J. Org. Chem. 1988; 53(21): 49394945. doi: $10.1021 / \mathrm{jo00256a008}$

d. Wagner J, Vieira E, Vogel P. Enantiomerically pure 7-oxabicylo[2.2.1] hept-5-en-zyl derivatives as synthetic intermediates.PartIII*.Total synthesis of D-and L-ribose derivatives. Helv. Chim. Acta. 1988; 71(3): 624-630. doi: 10.1002/hlca.19880710316

e. Hertel LW, Kroin JS, Misner JW, Tustin JM. Synthesis of 2-deoxy-2, 2-difluoro-D-ribose and 2-deoxy-2,2'-difluoro-D-ribofuranosyl nucleosides. J. Org. Chem. 1988; 53(11): 2406-2409. doi: 10.1021/ jo00246a002

58. a. Herdewijn $P$, Aerschot AV, Kerremans L. Synthesis of Nucleosides Fluorinated in the Sugar Moiety. The Application of Diethylaminosulfur Trifluoride to the Synthesis of Fluorinated Nucleosides. Nucleos. Nucleot. 1989; 8(1): 65-69. doi: 10.1080/07328318908054159

b. Hennen WJ, Wong CHA. A new method for the enzymic synthesis of nucleosides using purine nucleoside phosphorylase. J. Org. Chem. 1989; 54: 4692-4695. doi: 10.1021/jo00280a046

c. Ludwig J, Eckstein F. Rapid and efficient synthesis of nucleoside 5'-0-(1-thiotriphosphates), $\quad 5^{\prime}$-triphosphates and 2',3'-cyclophosphorothioates using 2-chloro-4H-1,3,2benzodioxaphosphorin-4-one. J. Org. Chem. 1989; 54(3): 631-635. doi: 10.1021/j000264a024

d. Yokoyama M, Yamada N. Synthesis of spiro and bicyclic nucleosides from ribose nitrile oxid with dimethyl acetylenedicarboxylate. Tetrahedron Lett. 1989; 30(28): 3675-3676. doi: 10.1016/S00404039(01)80480-9

59. Hutchinson DW. New approaches to the synthesis of antiviral nucleosides. Trends in Biotechnol. 1990; 8: 348-353. doi: 10.1016/0167-7799(90)90222J

60. Musicki B, Widlanski TS. Synthesis of Nucleoside Sulfonates and Sulfones. Tetrahedron Lett. 1991; 32(10): 1267-1270. doi: 10.1016/S00404039(00)79642-0
61. Beach JW, Jeong LS, Alves AJ, Pohl D, Kim HO, et al. Synthesis of enantiomerically pure (2'R,5'S)-(-)-1-(2-hydroxymethyloxathiolan-5-yl) cytosine as a potent antiviral agent against hepatitis B virus (HBV) and human immuno deficiency virus (HIV). J. Org. Chem. 1992; 57(8): 22172219. doi: 10.1021/jo00034a006

62. a. Matsuda A, Azuma A, Nakajima Y, Takenuki K, Dan A. Nucleos Nucleot as Antitumor Antiviral agents 1-22. New York Plenum Press. 1993.

b. Munier P, Picq D, Anker D. Trifluoromethylation of sugar 1,4-lactones : Synthesis of 5-deoxy-5,5,5-trifluoro-D and L-ribose and lyxose derivatives. Tetrahedron Lett. 1993; 34(51): 8241-8244. doi: 10.1016/ S0040-4039(00)61400-4

c. Waga T, Nishizaki T, Miyakawa I, Ohrui H, Meguro H. Synthesis of 4'-C-Methylnucleosides. Biosci. Biotech.Bioch. 1993; 57(9): 1433-1438. doi: $10.1271 /$ bbb. 57.1433

63. a. Lee-Ruff E, Wan W, Jiang J. A Novel Approach toward the Synthesis of Chiral 2,3-Dideoxy Nucleosides and Their Carbocyclic Analogs. J. Org. Chem. 1994; 59: 2114-2118. doi: 10.1021/jo00087a029

b. Kolb VM, Dworkin JP, Miller SL. Alternative bases in the RNA world: The prebiotic synthesis of urazole and its ribosides. J. Mol. Evol. 1994; 38: 549-557. doi: 10.1007/BF00175873

64. Prasad AK, Sorensen MD, Parmar VS, Wenge IJ. Tri-O-acyl 2-deoxy-Dribofuranose: An effective enzyme-assisted one-pot synthesis from 2-deoxy-D-ribose and transformation into 2'-deoxynucleosides. Tetrahedron Lett. 1995; 36(34): 6163-6166. doi: 10.1016/00404039(95)01216-5

65. Sekine $T$, Kawashima $E$, Ishido $Y$. Efficient synthesis of $D-[5-C-13]$ ribose from D-ribose and its conversion into [5'-C-13] nucleosides. Tetrahedron Lett. 1996; 37(43): 7757-7760. doi: 0.1016/0040-4039(96)01770-4

66. a. Mikhailov SN, Efimtseva EV, Gurskaya GV, Fomitcheva MV, et al. An efficient synthesis and physico-chemical properties of 2'-O-Dribofuranosylnucleosides, minor tRNA components. J. Carbohyd. Chem. 1997; 16(1): 75-92.

b. Choi YS, Kang BW, Lu R,Osawa M, Hattori T, et al. Synthesis of Sulfated Deoxy-Ribofuranans Having selective Anti-AIDS Virus Activity by RingOpening Copolymerization of 1,4-AnhydroRiboseDerivatives. Polym. J. 1997; 29: 374-379. doi: 10.1295/polymj.29.374

67. a. Zwart MR, Link JK, Künzel FD, Cristalli G, ljzerman ADP, et al. A Functional Screening of Adenosine Analogues at the Adenosine A2B Receptor: A Search for Potent Agonists. Nucleos. Nucleot. 1998; 17(6): 969-985. doi: 10.1080/07328319808004215

b. Volpini R, Camaioni E, Vittori S, Barboni L, catia L.et al. Synthesis of New Nucleosides by coupling of chloropurines with 2- and 3-deoxy derivatives of N-methyl-D-ribofuranuronamide. Helvetica. 1998; 81(1): 145-152. doi: 10.1002/hlca.19980810113

c. Shuto S, Shirato M, Sumita Y, Ueno Y, Matsuda A. Nucleosides and Nucleotides.173. Synthesis of Cyclic IDP-carbocyclic-ribose, a Stable Mimic of Cyclic ADP-ribose. Significant Facilitation of the Intramolecular Condensation Reaction of N-1-(Carbocyclic-ribosyl)inosine 5',6"-Diphosphate Derivatives by an 8-Bromo-Substitution at the Hypoxanthine Moiety. J. Org. Chem. 1998; 63(6): 1986-1994. doi: 10.1021/j09717797

d. Izawa K, Shiragami H. Practical syntheses of antiviral nucleosides. Pure Appl. Chem. 1998; 70(2): 313-318. doi: 10.1351/pac199870020313

e. Mikhailov SN, Rodionov AA, Efimtseva EV, Ermolinsky BS et al. Formation of Trisaccharide Nucleosides During Disaccharide Nucleoside Synthesis. Eur. J. Org. Chem. 1998; 10: 2193-2199. doi: 10.1002/ (SICI)1099-0690(199810)1998:10<2193:AID-EJOC2193>3.0.CO;2-3

f. Efimtseva EV, Victorova LS, Rodionov AA, Ermolinskyl BS, et al Disaccharide Nucleosides And Their Enzymatic And Chemical Incorporation Into Oligonucleotides. Nucleos Nucleot. 1998; 17(9-11): 1681-1684. doi: 10.1080/07328319808004701

g. Griffin FK, Murphy PV, Paterson DE, Taylor RJK. A Ramberg-Bäcklund approach to exo-glycals. Tetrahedron Lett. 1998; 39(44): 8179-8182. doi: 10.1016/S0040-4039(98)01822-X 
68. a. Vorbrüggen $\mathrm{H}$, Ruh-Pohlenz C. Synthesis Of Nucleosides. Org. React. 1999; 55: 1-30. doi: 10.1002/0471264180.or055.01

b. Mc Ewan JF, Veitch HS, Russell-Jones GJ. Synthesis and Biological Activity of Ribose-5'-Carbamate Derivatives of VitaminB12. Bio conjugate Chem. 1999; 10(6): 1131-1136. doi: 10.1021/bc990086p

c. Fleetwood A, Hughes NA. Convenient synthesis of 2, 3-O-isopropylidene5-thio-D-ribose and 5-thio-D-ribose; Synthesis of 1, 4-anhydro-2,3-Oisopropylidene- $\alpha$-D-ribopyranose and 1,4-anhydro-2,3-Oisopropylidene-5-thio- $\alpha$-D-ribopyranose. Carbohydr. Res. 1999; 317(1-4): 204-209. doi: 10.1016/S0008-6215(99)00064-6

69. a. Vittori S, Lorenzen A, Stannek C, Costanzi S, Volpini C,et al. N-Cycloalkyl Derivatives of Adenosine and 1-Deazaadenosine as Agonists and Partial Agonists of the A1 Adenosine Receptor. J. Med. Chem. 2000; 43(2): 250-260. doi: 10.1021/jm9911231

b. Crimmins MT, King BW, Zuercher WJ, Choy AL. An Efficient, General Asymmetric Synthesis of Carbocyclic Nucleosides:Application of an Asymmetric Aldol/Ring-Closing Metathesis Strategy. J.Org Chem. 2000; 65(25): 8499-8509. doi: 10.1021/jo005535p

70. a. Shi ZD, Yang BH, Wu YL. A stereospecific synthesis of I-ribose and I-ribosides from d-galactose. Tetrahedron Lett. 2001; 42(43): 7651-7653. doi: 10.1016/S0040 4039(01)01623-9

b. Hawkins ME, P fleiderer W, Jungmann O, Balis FM. Synthesis and Fluorescence Characterization of Pteridine Adenosine Nucleoside Analogs for DNA Incorporation. Anal. Biochem. 2001; 298: 231-240. doi: 10.1006/abio.2001.5399

71. a. Efimtseva EV, Mikhailov SN. Disaccharide Nucleosides and Oligonucleotides on Their Basis. New Tools for the Study of Enzymes of Nucleic Acid metabolism. Biochem. Moscow. 2002; 67(10): 1136-1144. doi: 10.1023/A:1020963207320

b. Sivets GG, Klennitskaya TV, Zhernosek EV, Mikhailopulo I. Synthesis of Peracylated Derivatives of I-Ribofuranose from d-Ribose and Their Use for the Preparation of $\beta$-I-Ribonucleosides. Synthesis. 2002; 2: 253-259. doi: 10.1055/s-2002-19805

c. Moon HR, Choi WJ, Kim HO, Jeong LS. Improved and alternative synthesis of D- and L-cyclopentenone derivatives, the versatile intermediates for the synthesis of carbocyclic nucleosides. Tetrahedron: Asym. 2002; 13(11): 1189-1193. doi: 10.1016/S0957-4166(02)00316-6

d. Fuentes J, Angulo M,Pradera MA. Fluoronucleosides,Isothiocyanato C-Nucleosides, and Thioureylene Di-C-nucleosides via Cyclic Sulfates. J. Org. Chem. 2002; 67(8): 2577-2587. doi: 10.1021/jo0110303

e. Karpeisky A, Sweedler D, Haeberli P, Read J. Scaleable and efficient synthesis of 2'-deoxy-2'-N-phthaloyl nucleoside phosphoramidites for oligonucleotide synthesis. J. Bio.org.Med.Chem. Lett. 2002; 12: 33453347. doi: 10.1016/S0960-894X(02)00744

f. Khudyakov YE, Fields HA. The Quarterly Review of Biology.Artificial DNA. Methods and Applications CRC Press. 2002; 77(1): 0-8493-1426-7.

72. a. Schmidt J, Eschgfaller B, Benner SA. A Direct Synthesis of Nucleoside Analogs Homologated at the 3'- and 5'-Positions. Helv. Chim. Acta. 2003; 86: 2937-2958. doi: 10.1002/hlca.200390243

b. Kundu MK, Földesi A, Chattopadhyaya J. Studies on the Stereo selective Synthesis of Deuterated D-Ribose Derivatives. Helv Chim Acta. 2003; 86(3): 633-643. doi: 10.1002/hlca.200390062

73. a. Napoli DL, Fabio GD, D'Onofrio J, Montesarchio D. New NucleosideBased Polymeric Supports for the Solid Phase Synthesis of RiboseModified Nucleoside Analogues. Synlett. 2004; 11: 1975-1979. doi: 10.1055/s-2004-830864

b. Johnson DC, Widlanski TS. Current Protocols in Nucleic Acid chemistry. Curr Protoc Nucleic Acid. Chem. 2004. doi: 10.1002/0471142700. nc1301s15

c. Gu X, Yang Z, Zhang L, Kunerth S, Fliegert R, et al. Synthesis and Biological Evaluation of Novel Membrane-Permeant Cyclic ADP-Ribose Mimics: N1-[(5'-OPhosphorylethoxy)methyl]-5'-O-phosphorylinosine $5^{\prime}, 5^{\prime \prime}$-Cyclicpyrophosphate (cIDPRE) and 8-Substituted Derivatives. J. Med Chem. 2004; 47(23): 5674-5682. doi: 10.1021/jm040092t
74. a. Sridhar PR Saravanan V,Chandrasekaran S. Chemistry of tetrathiomolybdate and te traselenotung state: Applications in carbohydrate chemistry. Pure. Appl. Chem. 2005; 77(1): 145-153. doi: 10.1351/pac200577010145

b. Wagner GK, Guse AH, Potter BV. Rapid Synthetic Route toward Structurally Modified Derivatives of Cyclic Adenosine 5'-Diphosphate Ribose. J. Org.Chem. 2005; 70(12): 4810-4819. doi: 10.1021/jo050085s

c. Larsen $\mathrm{CH}$, Ridgway BH, Shaw JT, Smith DM, Woerpel KA. Stereo selective C-Glycosylation Reactions of Ribose Derivatives: Electronic Effects of Five-Membered Ring Oxocarbenium lons. J. Am. Chem Soc. 2005; 127(31): 10879-10884. doi: 10.1021/ja0524043

75. a. Romeo G, lannazzo D, Piperno A, Romeo R, Mastino A, et al. Synthesis and biological evaluation of phosphonated dihydroisoxazole nucleosides. Bio. org. Med. Chem. 2006; 14: 3818-3824. doi: 10.1016/j. bmc.2006.01.028

b. Cho HJ, Sung DH, Kim EJ, Yoon CH, KiCS, Kim JW, et al. Clinical and Genetic Analysis of Korean Patients with Miyoshi Myopathy: Identification of Three Novel Mutations in the DYSF Gene. J. Korean Med Sci. 2006; 21(4): 724-727. doi: 10.3346/jkms.2006.21.4.724

c. Horhota AT, Szostak JW, Mc Laughlin LW. Glycerol Nucleoside Triphosphates:Synthesis and Polymerase Substrate Activities. Org. Lett. 2006; 8(23): 5345-5347. doi: 10.1021/ol062232u

d. Kosiova I, Janicova A, Kois P. Synthesis of coumarin or ferrocene labeled nucleosides via Staudinger ligation. Beilstein. J.Org. Chem. 2006; 2(1): 23. doi: $10.1186 / 1860-5397-2-23$

76. a. Oliviero G, Amato J, D Errico S, Borbone N, Piccialli G, et al. Solid Phase Synthesis of Nucleo base and Ribose Modified Inosine Nucleoside Analogues. Nucleos. Nucleot. Nucl. 2007; 26(10-12): 1532-2335. doi: 10.1080/15257770701506608

b. Li Y, Mao S, Hager MW, Becnel KD, Schinazi RF, Liotta DC. Synthesis and evaluation of 2'-substituted cyclobutyl nucleosides and nucleotides as potential anti-HIV agents. Bio. org. Med. Chem. Lett. 2007; 17(12): 33983401. doi: 10.1016/j.bmcl.2007.03.094

c. Mackman RL, Boojamra CG, Prasad V, Zhang L, Lin KY, et al Synthesis,antiHIVactivity, and resistance profiles of ribose modified nucleoside phosphonates. Bio. org. Med. Chem. Lett. 2007; 17(24): 67856789. doi: 10.1016/j.bmcl.2007.10.038

77. a. Woodyer RD, Wymer NJ, Racine FM, Khan SN Saha BC. Efficient Production of L-Ribose with a Recombinant Escherichia coli Biocatalyst. Appl Environ Microbiol. 2008; 74(10): 2967-2975. doi: 10.1128/ AEM.02768-07

b. Warnecke S, Meier C. New and efficient Synthesis of Nucleoside Polyphosphates and Nucleoside Monophosphate Sugars. Nucleic Acids Symp Ser. 2008; 52(1): 583-584. doi: 10.1093/nass/nrn295

c. Kulikova IV, Muradova DA, Varilzhuk IS, Mikhailov. Stereospecific synthesis of 2'-O- $\alpha$-D-ribofuranosylnucleosides. SN. Collect. Symp. Ser. 2008; 10: 155-158. doi: 10.1135/css200810155

d. Melman A, Zhong $M$, Marquez VE, Jacobson KA. Synthesis of Enantiomerically Pure (S)-Methano carbaribo Uracil Nucleoside Derivatives for Use as Antiviral Agents and P2Y Receptor Ligands. J. Org. Chem. 2008; 73(20): 8085-8088. doi: 10.1021/jo801224j

78. a. Kulikova IV, Muradova DA, Mikhailov SN. Effective isomerisation of 3', $5^{\prime} \mathrm{O}$ (tetraisopropyldisiloxane-1,3-diyl) nucleosides in the presence of trimethylsilyl trifluoromethanesulfonate. Arkivoc. 2009; 158-170. doi: 10.3998/ark.5550190.0010.313

b. Cosyn L, Calenbergh SV, Joshi BV, Ko H, Carter RL, et al. Synthesis and P2Y Receptor Activity of Nucleoside 5'-Phosphonate Derivatives. Bio. org. Med. Chem. Lett. 2009; 19(11): 3002-3005. doi: 10.1016/j. bmcl.2009.04.027

c. Powner MW, Gerland B, Sutherland JD. Synthesis of activated pyrimidine ribonucleotides in prebiotically plausible conditions. Nature. 2009; 459: 239-242. doi: 10.1038/nature08013

d. Okano K. Synthesis and pharmaceutical application of L-ribose Tetrahedron. 2009; 65(10): 1937-1949. doi: 10.1016/j.tet.2008.11.047 
e. Helanto M, Kiviharju K, Granström T, Leisola M, Nyyssölä A. Biotechnological production of I-ribose from I-arabinose. Applied Microbio. and Biotech. 2009; 83(1): 77-83. doi: 10.1007/s00253-008$1855-x$

f. More JD, Campbell MG. Reaction of acetylated carbohydrates with trimethylaluminum: concise synthesis of 1,2-O-isopropylidene D-ribofuranose. Tetrahedron Lett. 2009; 50: 2617-2619. doi: 10.1016/j. tetlet.2009.03.116

g. Stalford SA, Kilner CA, Leach AG, Turnbull WB. Neighbouring group participation vs. addition to oxacarbenium ions: studies on the synthesis of mycobacterial oligosaccharides. Org. Biomol. Chem. 2009; 7(23): 4842-4852. doi: 10.1039/b914417j

79. Ding QB, Ou L, Wei DZ, Wei XK, Xu YM, et al. Enzymatic synthesis of nucleosides by nucleoside phosphorylase co-expressed in Escherichia coli. Zhejiang. J. Univ. Sci. 2010; 11(11): 880-888. doi: 10.1631/jzus. B1000193

80. a. Baldoni L, Stortz CA, Marino C. Synthesis and conformational analysis of 1,2-cis fused bicyclic $\alpha$-d-galactofuranosyl thiocarbamate from per-Otert-butyldimethylsilyl- $\beta$-d-alactofuranosyl isothiocyanate. Carbohydr. Res. 2011; 346(2): 191-196. doi: 10.1016/j.carres.2010.11.013

b. Muller CE, Jacobson KA. Recent developments in adenosine receptor ligands and their potential as noveldrugs. Biochim. Biophys. Acta. Biomembr. 2011; 1808(5): 1290-1308. doi: 10.1016/.jbbamem.2010.12.017

c. Kulik K, Radzikowska E, Kaczmarek R, Baraniak J, Stec WJ, Clercq ED, et al. Synthesis and an antiviral activity evaluation of nucleoside $5^{\prime}-\mathrm{O}-(\mathrm{N}$ acyl) phosphoramidates. Antivir. Chem. Chemother. 2011; 21(3): 143150. doi: $10.3851 /$ IMP1718

d. Caton-Williams J, Lin L, Smith M, Huang Z. Convenient synthesis of nucleoside5'-triphosphates for RNA transcription. Chem. Commun. 2011; 47: 8142-8144. doi: 10.1039/C1CC12201K

e. Ghoneim AA. Synthesis of some nucleosides derivatives from L-rhamnose with expected biological activity. Chem. Central. J. 2011; 5: 1-7. doi: 10.1186/1752-153X-5-7

f. Brulikova L, Hlavac J. Synthesis, reactivity and biological activity of 5-alkoxymethyluracil analogues. Beilstein J. Org. Chem. 2011; 7: 678698. doi: 10.3762/bjoc.7.80

g. Vembaiyan K, Pearcey JA, Bhasin M, Lowary TL, Zou W. Synthesis of sugar-amino acid-nucleosides as potential glycosyl transferase inhibitors. Bio.org. Med. Chem. 2011; 19(1): 58-66. doi: 10.1016/j. bmc.2010.11.044

h. Brodszki M, Bäckström B, Horvath K, Larsson T, Malmgrent H. Synthesis of the Hepatitis B Nucleoside Analogue Lagociclovir Valactate. Org. Process Res. Dev. 2011; 15(5): 1027-1032. doi: 10.1021/op200153s

81. a. Mohamady S, Taylor SD. Rapid and Efficient Synthesis of Nucleoside Polyphosphates and Their Conjugates Using Sulfonyl Imidazolium Salts. Curr. Protoc. Nucleic. Acid. Chem. 2012; 13: (11). doi: 10.1002/0471142700.nc1311s51

b. Voorde JV, Quintiliani M, Mc Guigan C, Liekens S, Balzarini J. Inhibition of pyrimidine and purine nucleoside phosphorylases by a 3,5-dichlorobenzoylsubstituted 2-deoxy-D-ribose-1-phosphate derivative. Biochem. Pharmacol. 2012; 83: 1358-1363. doi: 10.1016/j.bcp.2012.02.005

c. Lim YR, Yeom S, Oh DK. Production of L-Ribose from L-Ribulose by a Triple-Site Variant of Mannose Phosphate Isomerase from Geobacillus thermodenitrificans. Appl . Environ. Microbiol. 2012; 78(11): 3880-3884. doi: 10.1128/AEM.07012-11

d. Avanzo RE, Anesini C, Fascio ML, ErreaMI, D'Accorso NB. 1, 2, 4-Triazole D-ribose derivatives: design, synthesis and antitumoral evaluation. Eur. J. Med. Chem. 2012; 47(1): 104-110. doi: 10.1016/j.ejmech.2011.10.028

e. Stevens JD. Preparation and properties of the aldohexofuranose pentaacetates. Carbohydr. Res. 2012; 347(1): 9-15. doi: 10.1016/j. carres.2011.09.009

f. Vitali LA, Petrelli D, Lambertuc C, Prenna M, Volpini $R$, et al. In vitro antibacterial activity of different adenosine analogues. J. Med. Microbiol. 2012; 61: 525-528. doi: 10.1099/jmm.0.038174-0 g. Pati SR, Ahir K, Raman CV. Stereospecific synthesis of $\mathrm{C}$-arabinofuranosides and carba-disaccharide analogues of Motif $\mathrm{C}$ of cell wall AG complex of Mtb. Tetrahedron. Lett. 2012; 53(47): 6347-6350. doi: 10.1016/j.tetlet.2012.09.015

h. Almendros M, Berenguer J, Sinisterra JV. Thermus thermophilus Nucleoside Phosphorylases Active in the Synthesis of Nucleoside Analogues. Appl. Environ. Microbiol. 2012; 78(9): 3128-3135. doi: 10.1128/AEM.07605-11

i. Boyle GA, Edlin CD, Li Y, Liotta DC, Morgans GL,et al. Enantio selective synthesis of the carbocyclicnucleoside(-)-abacavir. Org. Biomol. Chem. 2012; 10(9): 1870-1876. doi: 10.1039/c2ob06775g

82. a. Efremova AS, Alexander LZ, Sharma IS, Kulikova VI, Drenichev SM, et al. Disaccharide Pyrimidine Nucleosides and Their Derivatives: A Novel Group of Cell-Penetrating Inhibitors of Poly(ADP-Ribose)Polymerase1. Nucleos. Nucleot. Nucl. 2013; 32: 510-528. doi: 10.1080/15257770.2013.827793

b. Kalachova L, Pohl R, Bednarova L, Fanfrlik J, Hocek M. Synthesis of nucleosides and dNTPs bearing oligopyridine ligands linked through an octadiyne tether, their incorporation into DNA and complexation with transition metalcations. Org. Biomol. Chem. 2013; 11: 78-89. doi: 10.1039/C2OB26881G

83. a. Sylla B, Gauthiera C, Legaulta J, Fleurya PY, Mshvildadzea SLV, et al. Isolation of a new disaccharide nucleoside from Helleborus caucasicus: structure elucidation and total synthesis of hellecaucaside $A$ and its ß-anomer. Carbohydr. Res. 2014; 398: 80-89. doi: 10.1016/j. carres.2014.06.027

b. Liu G, Gong S,Yang Q, Sun Q. Synthesis of Nucleoside 5'-H-Phosphonothioates via Nucleoside5'-Phosphinate Intermediates. Adv. Mater. Res. 2014; 848: 223-226. doi: 10.4028/www.scientific.net/ AMR.848.223

c. Peifer M, Berger R, Shurtleff VW, Conrad JC, Mac Millan DWC. A General and Enantioselective Approach to Pentoses: A Rapid Synthesis of PSI6130, the Nucleoside Core of Sofosbuvir. J. Am. Chem. Soc. 2014; 136: 5900-5903. doi: 10.1021/ja502205q

d. Fateev IV, Antonov KV, Konstantinova ID, Muravyova TI, Seela F, et al The chemoenzymatic synthesis of clofarabine and related 2'deoxyfluoroarabinosyl nucleosides: the electronic and stereo chemical factors determining substrate recognition by E. coli nucleoside phosphorylases. Beilstein J. Org. Chem. 2014; 10: 1657-1669. doi: 10.3762/bjoc. 10.173

e. Lei Y, Zhang D, Liu Y, Tian G, Ge H. Synthesis and X-Ray Structure of New Anticancer Nucleosides Basedon 1-((2-Hydroxyethoxy)methyl)-5(phenylthio)-1H-1,2,4-triazole-3-carboxamide. J. Crys.t Process. Technol. 2014; 4: 135-139. doi: 10.4236/jcpt.2014.43017

f. Kuchana R, Mamidyala SK, Mereyalaa HB. Synthesis of novel xylofuranosyloxy methyl nucleosides. Orient. J. Chem. 2014; 30(2): 409418. doi: $10.13005 / 0 j c / 300202$

84. a. Shaughnessy KH. Palladium-Catalyzed Modification of Unprotected Nucleosides,Nucleotides, and Oligonucleotides. Molecules. 2015; 20: 9419-9454. doi: 10.3390/molecules20059419

b. Kulikova IV, Muradova DA, Drenichev MS, Mikhailov SN. Stereoselective Synthesis of 2'-O- $\alpha$-D-Ribofuranosyluridine, A Structural Fragment of Hellecaucaside A. Chem. Nat. Compd. 2015; 51(2): 256-260. doi: 10.1007/s10600-015-1256-1

c. Downey AM, Richter C, Pohl R, Mahrwald R, Hocek M. Direct One-Pot Synthesis of Nucleosides from Unprotectedor 5-O-Monoprotected d-Ribose. Org. Lett. 2015; 17: 4604-4607. doi: 10.1021/acs. orglett.5b02332

d. Bergeron-Brlek M, Mean well M, Britton R. Direct synthesis of imino-Cnucleoside analogues and other biologically active iminosugars. Nat. Commun. 2015; 6: 6903-6308. doi: 10.1038/ncomms7903

e. Mahajan S, Manetsch R, Merkler DJ, Stevens SM. Synthesis and Evaluation of a Novel Adenosine-Ribose Probe for Global-Scale Profiling of Nucleoside and Nucleotide-Binding Proteins. PLOS ONE. 2015; 10(2): e0115644. doi: 10.1371/journal.pone.0115644 
f. Zupancic N, Ban Z, Matic J,Saftic D,Obrovac LG,et al. Synthesis and Biological Activity of Reversed Pyrimidine Nucleosides. Croat. Chem. Acta. 2015; 88(1): 43-52. doi: 10.5562/cca2531

g. Oliveira MP, Franco LL, Lima MCA, Simões $C M O$, et al. A New Straightforward Synthesis of 2', 3'-Didehydro-2', 3'-dideoxy-2'-(2"(trimethylsilyl)ethylthio) thymidine, Key Intermediate for the Synthesis of 2'-Substituted Thionucleosides. J. Braz. Chem. Soc. 2015; 26(4): 816821. doi: 10.5935/0103-5053.20150025

h. Bessieres M, Chevrier F, Roy V, Agrofoglio LA. Recent progress for the synthesis of selected carbocyclic nucleosides. Future Med. Chem. 2015; 7(13): 1809-1828. doi: 10.4155/fmc.15.105

85. a. Elzagheid MI. Synthesis And Applications Of Sugar Fluorinated Nucleosides. Int. J. Cur. Res. Rev. 2016; 8(13): 42-49.

b. Mohamady S, Taylor SD. Synthesis of Nucleoside Triphosphates from 2'-3'-Protected Nucleosides Using Trimetaphosphate. Org. Lett. 2016; 18(3): 580-583. doi: 10.1021/acs.orglett.5b03624

c. Janowsky A, Tosh DK, Eshleman AJ, Jacobson KA. Rigid Adenine Nucleoside Derivatives as Novel Modulators of the Human Sodium Symporters for Dopamine and Norepinephrine. J. Pharmacol. Exp.Ther. 2016; 357: 24-35. doi: 10.1124/jpet.115.229666 d. Kölmel DK, Barandun L, Kool ET. Efficient synthesis of fluorescent alkynyl C-nucleosides via Sonogashira coupling for the preparation of DNA-based polyfluorophores. Org. Biomol. Chem. 2016; 14: 6407-6412. doi: 10.1039/С6ОВ01199C

e. Singh S, Gajulapati V, Kim M, Goo JI, Lee KJ, et al. A Divergent Approach for the Synthesis of $d$ - and I-4'-Ethynyl Dioxolane Nucleosides with Potent Anti-HIV Activity. Synthesis. 2016; 48(18): 3050-3056. doi: 10.1055/s-0035-1561637

f. Jordheim LP, Durantel D, Zoulim F, Dumontet C. Advances in the development of nucleoside and nucleotide analogues for cancer and viral diseases. Nat. Rev. Drug Discovery. 2013; 12: 447-464. doi: 10.1038/ $\operatorname{nrd} 4010$

86. Trost BM, Kallander LS. A Versatile Enantioselective Strategy toward I-CNucleosides: A Total Synthesis of I-Showdomycin. J. Org. Chem. 1999; 64(15): 5427-5435. doi: 10.1021/jo990195x 